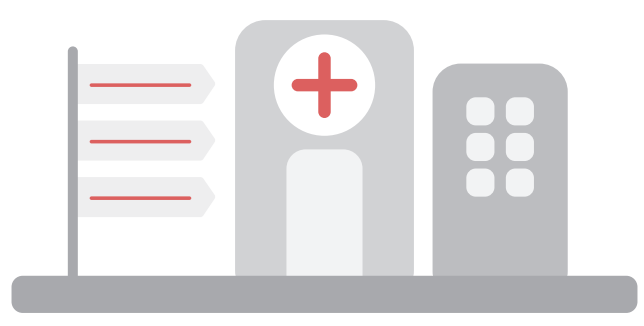

\title{
PROPOSTA DE METODOLOGIA DE PROJETO DE SINALIZAÇÃO PARA UM HOSPITAL UNIVERSITÁRIO FEDERAL
}

\author{
METHODOLOGICAL PROPOSAL OF SIGNALING PROJECT FOR A FEDERAL \\ UNIVERSITY HOSPITAL
}

\author{
Ludmila Wanbergna Nogueira Felix \\ Mestra em Gestão e Inovação em Saúde pela Universidade Federal do Rio Grande do Norte. \\ E-mail: ludmilawnf@gmail.com \\ Lana Carolina Silva Pereira \\ Designer pela Universidade Federal do Ceará. E-mail: lanacarolinasp@gmail.com \\ Marcela Barbosa Batista \\ Graduanda em Administração pela Universidade Federal do Ceará. \\ E-mail: marcela_barbosa2801@hotmail.com \\ Sarah Wellingda Santos Serafim
}

Administradora pela Universidade de Fortaleza e secretária executiva pela Universidade Federal do Ceará.

E-mail: sarahwellsantos@hotmail.com

Paulo Jorge Alcobia Simões

Doutor em Design de Comunicação pela Faculdade de Belas Artes da Universidade de Lisboa.

E-mail: p08alcobia@gmail.com

Danilo Alves Pinto Nagem

Doutor em Engenharia Mecânica pela Universidade Federal de Minas Gerais.

E-mail: danilo.nagem@gmail.com
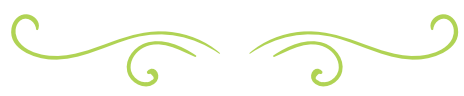

\section{RESUMO}

Este artigo apresenta uma proposta metodológica de projeto de sinalização para um hospital universitário federal. A contribuição metodológica é dividida em três etapas fundamentais: planejamento (construção de rede de apoio e realização de diagnóstico situacional), desenvolvimento (elaboração de projeto de sinalização, desenvolvimento de processo licitatório, validação de conteúdo e fechamento de manual de sinalização e ambientação) e execução (implantação de projeto de

sinalização e avaliação de proposta pela comunidade hospitalar). O método é inovador por acrescentar à proposta a construção de uma rede de apoio, que inclui formação de equipe operacional a partir de parcerias, estratégias de envolvimento da gestão e da comunidade hospitalar no processo, e oportunidades de captação de recursos na esfera pública, o que reduz drasticamente os custos do projeto às instituições. A proposta é apresentada em detalhes ao longo deste artigo e vem para dar suporte aos gestores que 
desejam desenvolver projetos de sinalização e não têm conhecimento técnico, equipe nem recursos financeiros para executá-los.

Palavras-chave: Sinalização hospitalar. Projeto de sinalização. Metodologia de design. Wayfinding.

\section{ABSTRACT}

This article presents a methodological proposal of signaling project for a federal university hospital. The methodological contribution is divided into threefundamental stages: planning (support network construction and realization of situational diagnosis), development (elaboration of signaling project, development of bidding process, validation of content and closure of manual of signaling and setting) and implementation (signaling project implementation and proposal evaluation by the hospital community). The method is innovative by adding to the proposal the construction of a support network, which includes training of operational staff from partnerships, strategies for involving management and the hospital community in the process, and opportunities for raising funds in the public sphere, which drastically reduces project costs to institutions. The proposal is presented in detail throughout the article and comes to support managers who wish to develop signaling projects and do not have the technical knowledge, staff or financial resources to execute it.

Keywords: Hospital signage. Signage design. Design methodology. Wayfinding

\section{INTRODUÇÃO}

Quando alguém busca um hospital para atendimento, não está no seu melhor estado físico-emocional. Portanto, quer encontrar um ambiente eficiente, acolhedor, organizado e bem sinalizado, que the permita encontrar o que procura - seja ambulatório, centro cirúrgico, área de exames, etc. - o mais rapidamente possível. O Hospital Universitário Walter Cantídio (HUWC), que é referência em atendimento de alta complexidade no Ceará e em transplantes na América Latina, deveria ser assim.

Dentro do hospital, já são conhecidos alguns casos de usuários que perderam procedimentos devido à sinalização deficiente e, em determinadas situações, ausente. Um paciente de 55 anos, natural do interior do Ceará, relata que, no dia marcado para a realização da cirurgia de catarata no HUWC, teve o procedimento cancelado porque não conseguiu localizar e chegar a tempo ao centro cirúrgico. Isso aconteceu, segundo ele, por falta de uma sinalização clara no hospital. Outros casos semelhantes já foram registrados, que também envolveram suspensão de cirurgia. Assim, apesar de ainda não pontuar de forma expressa no indicador de suspensão cirúrgica, o problema existe e afeta a produtividade do hospital, conforme relatos de pacientes e funcionários.

A própria literatura reconhece que são muitos os prejuízos, inclusive financeiros e de tempo, quando um hospital não dispõe de um projeto de sinalização eficaz e eficiente. Ulrich et al. (2004) realizaram um estudo em um hospital dos Estados Unidos, onde médicos e colaboradores das áreas administrativas perderam cerca de 4.500 horas por ano orientando pacientes a se localizarem ou a encontrarem unidades específicas dentro do hospital. Em 2004, portanto, o hospital gastou US $\$ 202,000$ das horas trabalhadas de seus funcionários com orientações a usuários, o equivalente a quase duas jornadas completas de um médico iniciante durante um ano.

Cabe salientar que os profissionais que trabalham no hospital também precisam de um ambiente que facilite o seu fluxo e contribua para a sua sanidade, tendo em vista os altos índices de estresse e pressão inerentes às profissões de saúde. Além disso, com a prática de contratação 
de serviços terceirizados, a rotatividade de funcionários dentro dos hospitais tem aumentado, especialmente em atividades-meio, como portaria e zeladoria. Desse modo, como não há tempo hábil para se familiarizar com o ambiente, a existência de uma sinalização facilitaria o entendimento do espaço, além de contribuir para o sentimento de pertencimento.

Neste trabalho será apresentado o estudo de caso do HUWC para o desenvolvimento do projeto de sinalização, englobando desde - levantamento das reais dificuldades dos pacientes até a burocracia para execução do projeto, como a captação de recursos, finalizando com a elaboração de um protocolo que pode ser usado por todos os hospitais da Rede Ebserh no desenvolvimento dos seus respectivos projetos de sinalização. Para tanto, este texto apresenta, no seu segundo capítulo, a revisão da problemática da sinalização encontrada no HUWC e em outros hospitais da Rede Ebserh.

No terceiro capítulo, é apresentada a metodologia das pesquisas teórica e prática envolvidas no estudo e, posteriormente, as ações realizadas para execução da proposta. Os resultados apresentados são as planilhas de gerenciamento de conteúdo, as plantas baixas do hospital, as atividades realizadas, as documentações produzidas, os apoios obtidos, o manual de sinalização e ambientação do HUWC, entre outros. Vários dos arquivos estão anexados e disponíveis para download a fim de possibilitar uma visualização de todo o trabalho realizado.
O HUWC está localizado numa área repleta de diversos prédios de saúde, como a Maternidade-Escola Assis Chateaubriand (Meac), as faculdades de Medicina (Famed) e Farmácia, Odontologia e Enfermagem (FFOE), o Centro de Hematologia e Hemoterapia do Ceará (Hemoce), o Instituto do Câncer do Ceará (ICC), a Unidade de Atenção Primária à Saúde Anastácio Magalhães (UAPS) e o Centro de Especialidades Odontológicas Rodolfo Teófilo (CEO). O hospital também divide espaço com instituições de apoio a pacientes, residências, comércios, vendedores ambulantes e estacionamentos formais e informais. Um caos em termos de organização. Na Figura 1, é possível verificar essa organização e conferir que a movimentação entre os prédios não deve ser uma tarefa muito simples.

O HUWC é da Universidade Federal do Ceará e, após assinatura de contrato da UFC com a Empresa Brasileira de Serviços Hospitalares em novembro de 2013, passou a ser administrado pela Ebserh, estatal criada para fazer a gestão e reestruturar os hospitais universitários federais. Os números do Walter Cantídio impressionam. De acordo com o Setor de Planejamento do hospital, são 18.234 consultas, 29.558 exames laboratoriais e de imagem e 420 procedimentos cirúrgicos, em média, por mês. A comunidade hospitalar é formada por 1.747 colaboradores próprios, entre empregados e servidores públicos federais; 590 terceirizados; 298 residentes médicos e multiprofissionais; e 69 estagiários. 


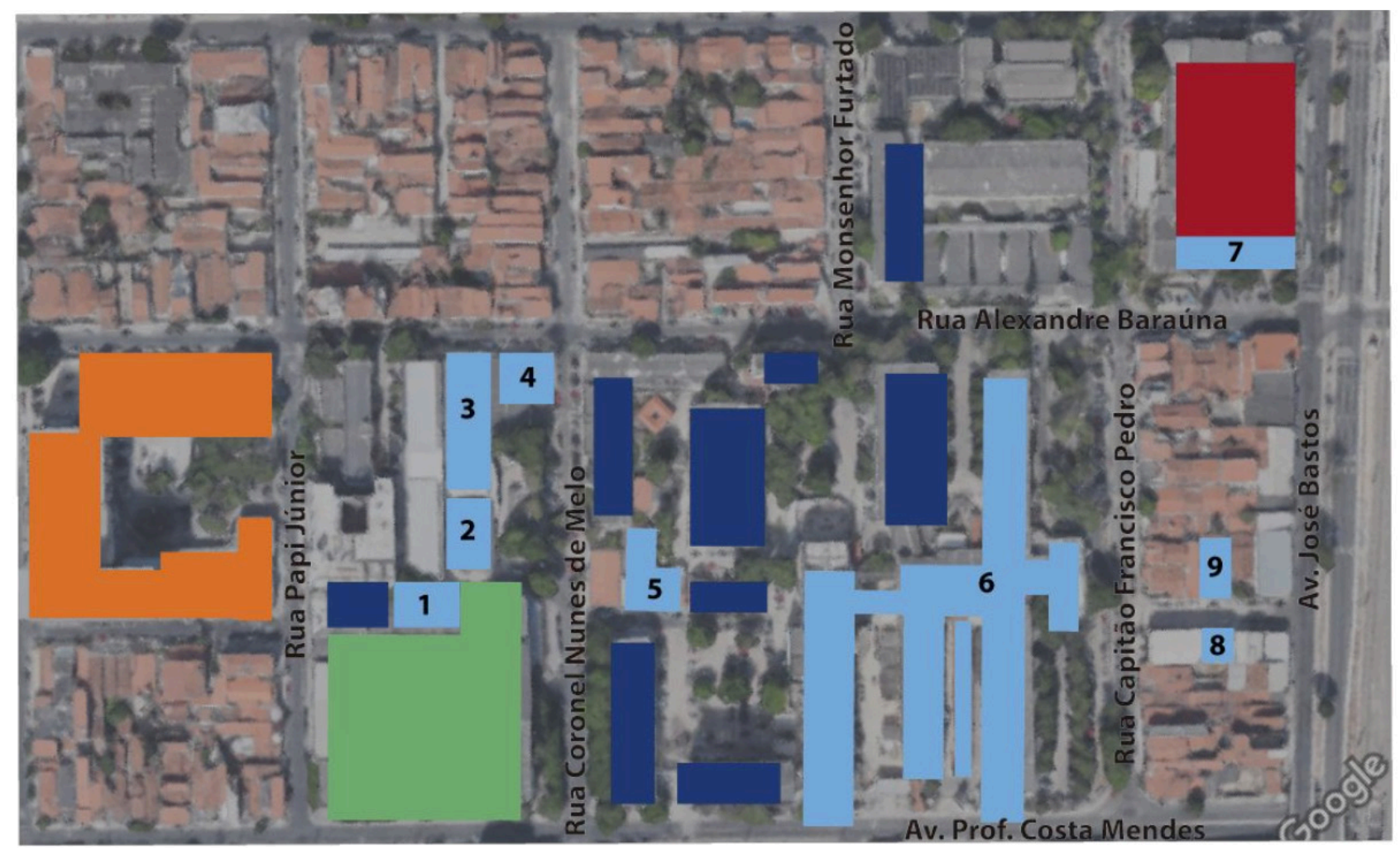

Legenda:

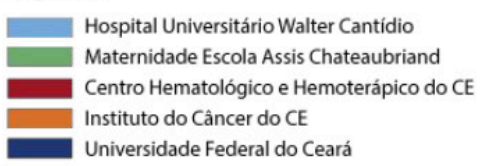

1. Ambulatórios de Pediatria e Geriatria

2. Ambulatório de Cirurgia

3. Ambulatórios Especializados (Illhas)

4. Ambulatório de Traumato-ortopedia e Transplante Renal

5. Ambulatório de Transplante Hepático
6. Prédio Principal do HUWC

7. Ambulatório de Onco-hematologia do HU

8. Jurídico e Planejamento

9. Oftalmologia

Figura 1 - Vista aérea da região onde o HUWC está inserido Fonte: Google Maps adaptado pela Unidade de Comunicação Social do HUWC.

Esses milhares de pessoas circulam diariamente no HUWC, que está espalhado em nove construções, como visto na Figura 1. Esse é o resultado de um hospital que nasceu em 1959 e, ao longo de quase 60 anos, cresceu sem um plano diretor adequado, conforme os ganhos de território de seus gestores e seu corpo assistencial. Desse modo, há casos de pacientes que são consultados num prédio $A$, fazem exames num prédio $B$ e buscam medicação num prédio C. Os totens físicos, que deveriam facilitar a conexão entre as construções, estão com informações desatualizadas e, em muitos casos, não existem (Figura 2a). Nem mesmo há identificação em fachadas (Figura 2b).
Internamente, a situação é igualmente complexa. Os setores, na sua maioria, não são identificados. Também não existem elementos de sinalização que façam conexão entre esses setores. Há portas sem nenhuma sinalização e outras com mensagens em excesso (Figura 2c). Ademais, existem espaços comuns, como salas de estudos, que recebem diversas denominações nos setores, conforme convém ao gestor da unidade. Não há uma gestão centralizada da sinalização, o que dá liberdade para que cada célula institucional sinalize seu espaço a partir de uma lógica própria. 


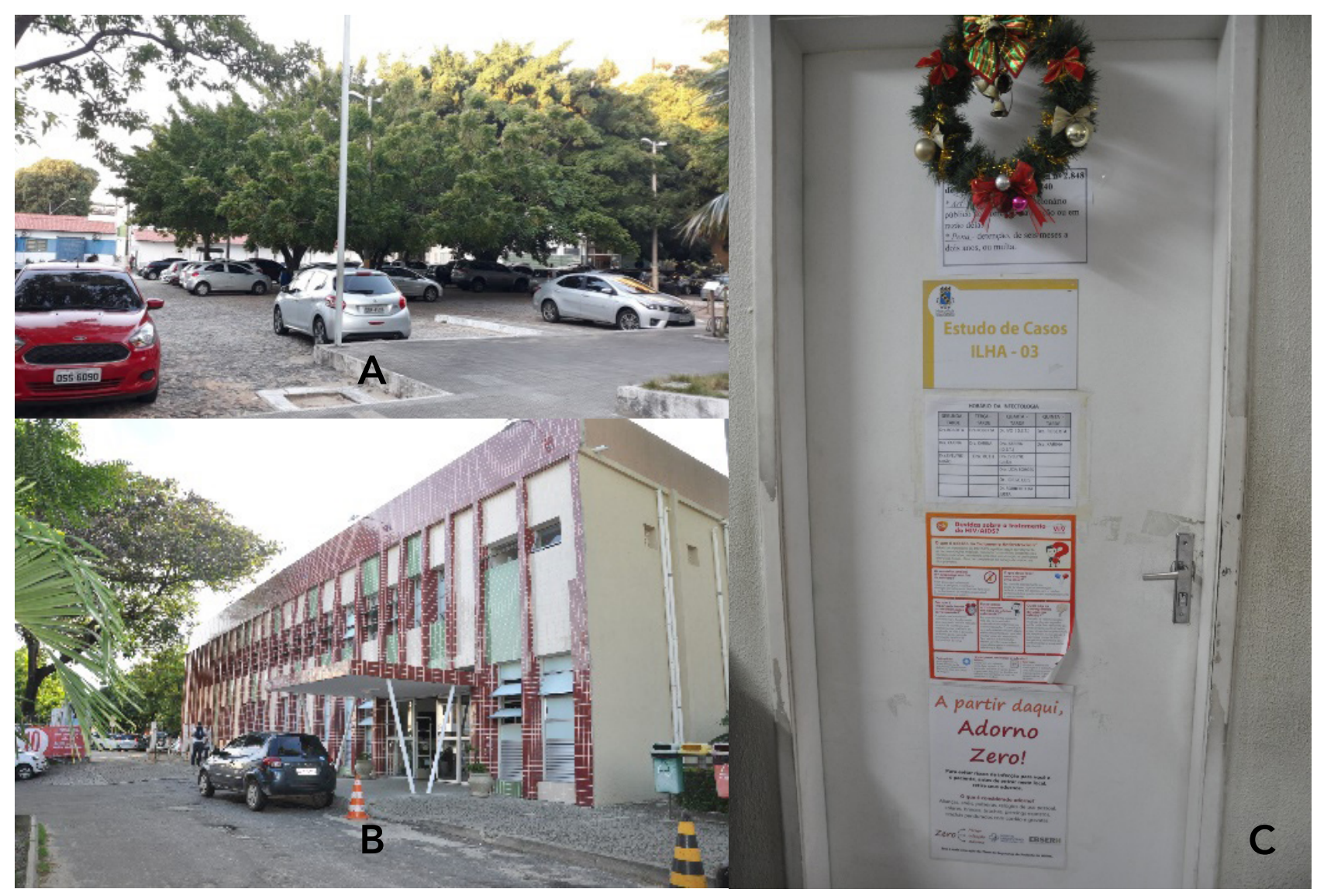

Figura 2 - Problemas de sinalização do HUWC: a) Ausência de totem físico para conectar prédios localizados no entorno do estacionamento da área de exames; b) Fachada do bloco central não identificada; c) Porta de um dos ambulatórios especializados com excesso de mensagens (Unidade de Comunicação Social do HUWC)

Fonte: Unidade de Comunicação Social do HUWC.

Nesse cenário, existem registros de: pacientes que perderam cirurgia porque não conseguiram sair da recepção e chegar ao centro cirúrgico a tempo de o procedimento começar, visto que se perderam no meio do caminho; usuários idosos que desistiram de buscar o medicamento no mesmo dia da consulta cardiológica por terem dificuldade de encontrar a farmácia ambulatorial; pacientes com limitações físico-mentais que tiveram muita dificuldade de encontrar o que procuravam; e aprovados que quase perderam a oportunidade de assumir um cargo público no HUWC porque não sabiam nem conseguiam informação correta com funcionários sobre o local de entrega da documentação.

Uma estagiária de Jornalismo da Unidade de Comunicação Social (UCS), logo nos primeiros dias de trabalho, aceitou o desafio de encontrar três ambulatórios do HUWC (vídeo da experiência disponível em <https://youtu.be/t5RJ419sib8>). Ela demorou 1 hora e 30 minutos para descobrir a localização dos espaços. Trata-se de uma menina de 20 e poucos anos, com um bom nível de instrução, desinibida e sem nenhuma limitação física.

Se pessoas como ela têm dificuldades de se localizar e se orientar no hospital, o quão frustrante e estressante deve ser a experiência de ir ao HU pela primeira vez para quem não tem nenhuma instrução, apresenta deficiência física ou é idoso? Além disso, os profissionais que trabalham na unidade de saúde também são submetidos a situações diárias de estresse e pressão. Afinal de contas, suas decisões podem ou não salvar vidas. Trabalhar num ambiente desorganizado e confuso, onde eles precisam interromper suas atividades para orientar 
pessoas, só contribui para uma qualidade de vida laboral cada vez mais impossível.

A situação piora quando o hospital apresenta uma alta rotatividade de terceirizados cujos postos de trabalho são em recepções e portarias. Ou seja, quem deveria informar sequer tem a oportunidade de se familiarizar aos espaços para os quais precisa orientar pessoas a chegar. São situações que ainda não pontuam expressamente nos indicadores de produtividade do hospital, mas que podem um dia trazer (como, de fato, já têm trazido) diversos transtornos a todos os públicos que precisam do HUWC.

Essa não é uma realidade exclusiva do Hospital Universitário Walter Cantídio. Na Figura 3, pode-se observar que os problemas relatados não são exclusivos de uma única região ou hospital, estando espeIhados em toda a rede da estatal. Além dos problemas já relatados por pacientes e colaboradores, a sinalização deficiente e sem padrão pode dificultar, inclusive,
- fortalecimento institucional da empresa estatal, criada em 2011 e desejosa de um reconhecimento nacional. A necessidade de sinalização e de padronização desse sistema nas unidades hospitalares geridas pela Ebserh é reconhecida pela Coordenadora de Comunicação Social, em Brasília.

Além das necessidades de usuários, dos profissionais e da própria Ebserh, há uma série de normas que determinam como deve ser a sinalização de segurança e saúde no trabalho em unidades como - HUWC para situações de risco, como incêndio. Toda essa legislação determina, por exemplo, que materiais devem ser utilizados nessa sinalização, considerando a facilidade de limpeza e a eliminação de contaminação. Nessa perspectiva, a Norma Regulamentadora $n^{\circ} 10$, do Ministério do Trabalho e Emprego, é uma das normativas em vigor relacionadas ao tema e contempladas neste trabalho (MINISTÉRIO DO TRABALHO E EMPREGO, 2016).

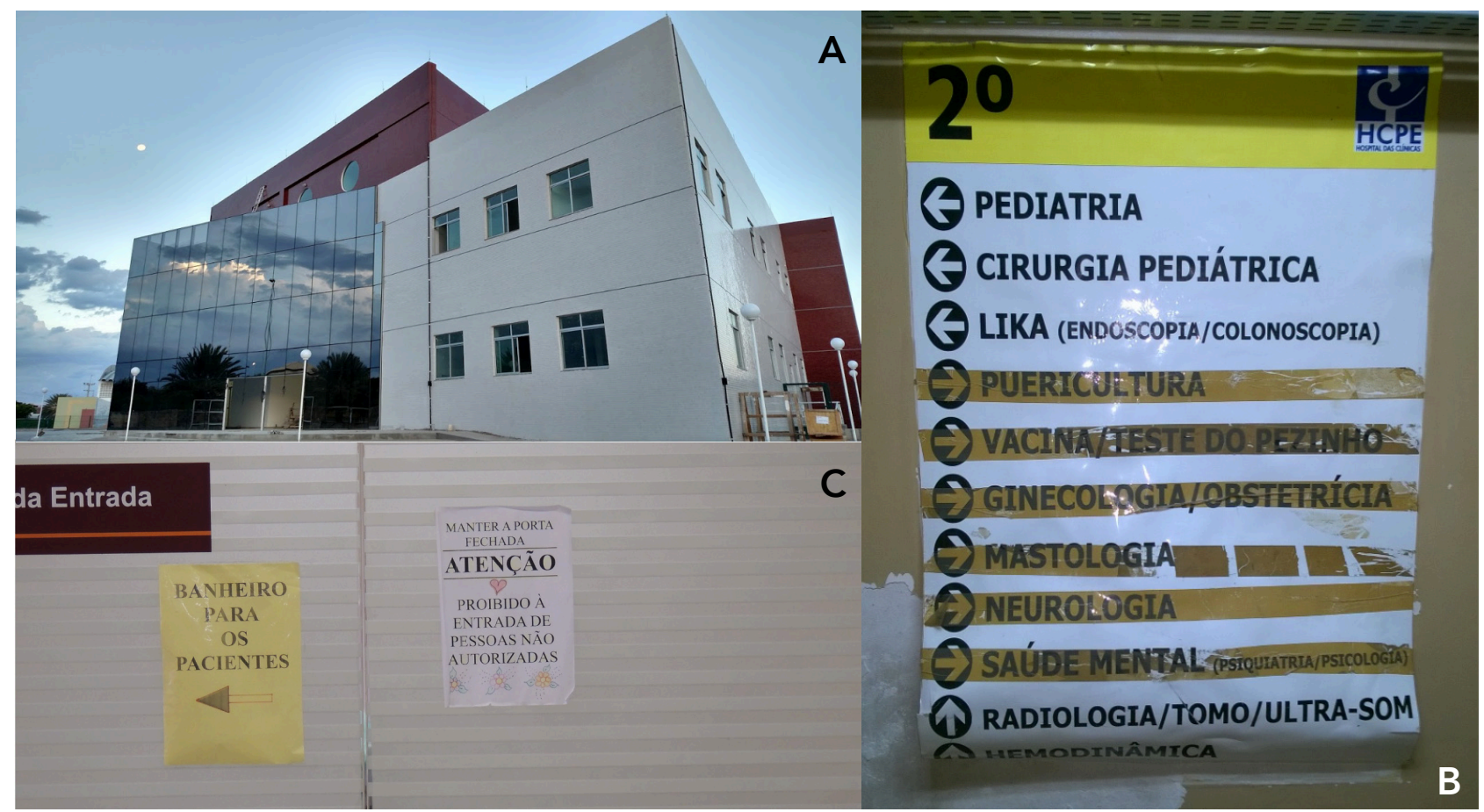

Figura 3 - Problemas de sinalização em hospitais da Rede Ebserh: a) Ausência de identificação de fachada em policlínica da Universidade Federal do Vale do São Francisco; b) Sinalização informal e deficitária em corredor do Hospital das Clínicas de Pernambuco; c) Sinalização informal de acesso restrito e indicação de banheiro para pacientes no Complexo Hospital de Clínicas da Universidade Federal do Paraná 
Baseado nos problemas apontados neste artigo, será apresentada uma proposta de metodologia de trabalho para ajudar gestores de hospitais públicos e de outras instituições de complexidade estrutural similar a conseguirem desenvolver, por meio de uma rede de apoio, projetos de sinalização próprios para as suas instituições a partir de um projeto- piloto realizado no Hospital Universitário Walter Cantídio. Como objetivos específicos, a presente pesquisa se propõe a realizar um diagnóstico situacional da sinalização existente no HUWC, construir o projeto de sinalização da unidade hospitalar e desenvolver um manual de sinalização e ambientação do HUWC.

\section{MATERIAIS E MÉTODOS}

Dentro da metodologia aplicada para o desenvolvimento do trabalho, foram realizados, em sinergia, o estudo teórico e o planejamento prático. No teórico, focou-se nas análises de artigos científicos, teses e livros correlatos, com a realização de uma pesquisa bibliográfica a partir de refinamento com as palavras-chave "hospital, design, sinalização e wayfinding. Segundo Fewings (2001), wayfinding é o processo de encontrar um destino, conhecido ou não, no menor intervalo de tempo possível, com o apoio de indicações oferecidas pelo entorno físico As buscas foram realizadas nas seguintes bases de dados: Emerald Insight, Lilacs, Molecular Diversity Preservation International (MDPI), Project Muse, PubMed, Sage Journals Online, Science Direct, Scopus, Sumários. org e Wiley Online Library. Foram incluídos artigos originais indexados no período de 2013 a 2017 nas línguas portuguesa, inglesa e espanhola. Aplicados esses critérios, foram encontrados 57 trabalhos (GUERRA NETO et al., 2018).

Após levantamento bibliográfico, foram identificadas as seguintes metodologias de design com foco em sistemas de sinalização: Follis e Hammer (1979), Mollerup (2005), Uebele (2007), Calori (2007), Smitshuijzen (2007), Costa (2007), Chamma e Pastorelo (2007), Gibson (2009) e D'Agostini (2017). Com base nas metodologias estudadas, propôs-se um método dividido em três etapas fundamentais: planejamento, desenvolvimento e, finalmente, execução, que estão descritas a seguir, assim como suas subetapas. Como primeira tarefa do projeto foi proposto um cronograma para se acompanhar o desenvolvimento de cada uma dessas etapas (Figura 4). 


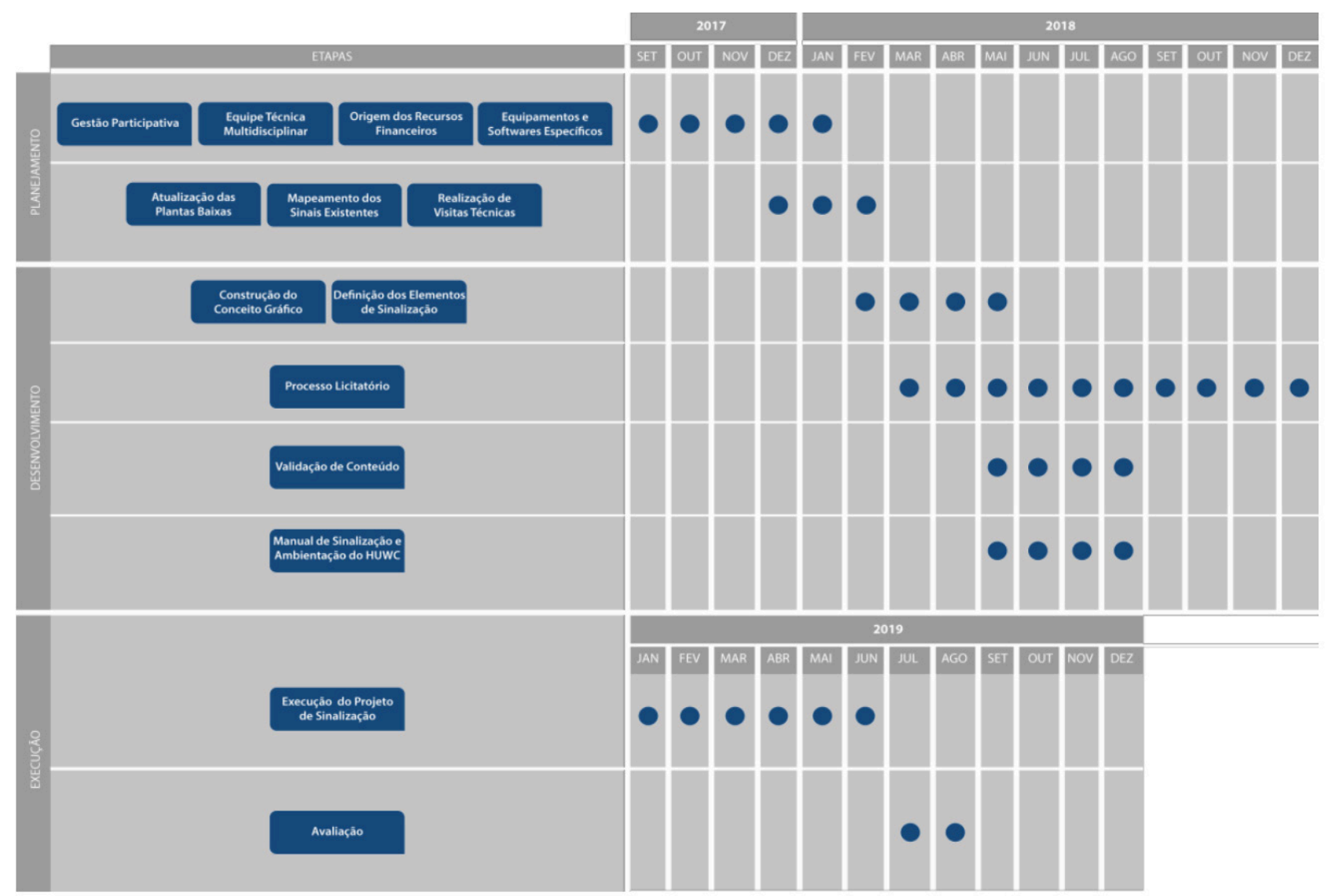

Figura 4 - Cronograma de execução das etapas da metodologia do projeto de sinalização do Hospital Universitário Walter Cantídio

Fonte: Autoria própria.

\section{Planejamento}

Esta etapa é formada pela construção da rede de apoio e pelo diagnóstico situacional. A construção da rede de apoio é formada pela gestão participativa, equipe técnica multidisciplinar, equipamentos e softwares específicos, e origem dos recursos financeiros. O diagnóstico situacional é determinado por meio da atualização das plantas baixas, do mapeamento da sinalização existente e da realização de visitas técnicas.

\section{Rede de apoio}

\section{- Gestão participativa}

A partir da vivência no Hospital Universitário Walter Cantídio, observou-se a necessidade do envolvimento da gestão da instituição com o projeto de sinalização, uma vez que a iniciativa necessita de tomadas de decisão que envolvem o funcionamento do próprio hospital, um volume expressivo de recursos e outras definições gerenciais. Além disso, propôs-se a criação de um grupo de trabalho (GT de Sinalização), envolvendo áreas estratégicas da instituição para facilitar as aprovações internas e as tomadas de decisões técnicas.

- Equipe técnica multidisciplinar

A Unidade de Comunicação Social do HUWC conta apenas com uma jornalista e duas assistentes administrativas sem formação em Design e/ou Arquitetura. Com isso, a necessidade de aumentar e qualificar a equipe técnica do projeto foi evidenciada. Dentro do planejamento para a formação dessa equipe foi proposta a busca por parceiros internos, como do Setor de Infraestrutura (SIF), e externos ao hospital, como dos cursos de Arquitetura e Design da Universidade 
Federal do Ceará. Essas parcerias foram necessárias para a atualização - em alguns casos, até mesmo criação - das plantas baixas do hospital, bem como para a concepção gráfica do projeto e a sistematização do conteúdo dos elementos de sinalização.

\section{- Equipamentos e softwares específicos}

Com o aumento da equipe técnica, foram necessárias mais estações de trabaIho e a liberação de softwares para edição de imagens e criação de desenhos arquitetônicos (Illustrator, Indesign, Photoshop e Autocad). Essa demanda foi formalizada à gestão do HUWC.

\section{- Recursos financeiros}

A questão financeira foi um entrave importante, já que a gestão do hospital não possuía recursos para esse tipo de projeto, apesar de apoiá-lo. Dessa forma, buscou-se outras possibilidades de financiamento, como as emendas parlamentares. A fim de dar início à tentativa de pleitear verbas para a execução do projeto, por iniciativa da Unidade de Comunicação Social, em setembro de 2017, foi feito um levantamento dos perfis dos deputados que formavam a bancada do Ceará na Câmara Federal, sendo escolhida uma parlamentar por apresentar vínculo formal com a UFC - professora licenciada da universidade.

\section{Diagnóstico situacional}

- Atualização das plantas baixas

As plantas baixas existentes foram disponibilizadas pelo Setor de Infraestrutura do HUWC. A partir de visitas previamente agendadas pela arquiteta do SIF, acompanhada pelo estagiário de Arquitetura e por um colaborador com profundo conhecimento da dinâmica de cada setor do hospital, foram feitas anotações nos documentos, como registro de novos espaços, exclusão de antigos e medições. As informações coletadas durante as visitas foram utilizadas para a atualização das plantas baixas em software específico (Autocad). Os documentos atualizados foram entregues à Unidade de Comunicação Social.

A liberação da arquiteta, dos colaboradores dos setores e das plantas baixas foi possível a partir da autorização da Superintendência do Complexo Hospitalar da UFC. Como sugestão do GT de Sinalização, para fortalecer ainda mais a proposta e garantir o comprometimento das chefias, foi enviado memorando da Superintendência à cada unidade, apresentando o projeto e suas etapas e pedindo o apoio de todos na execução de cada fase.

- Mapeamento dos sinais

Com as plantas atualizadas em mãos, a equipe de Comunicação Social visitou os setores para identificar os sinais existentes e ouvir as necessidades de sinalização apontadas pelas unidades. Nessa fase, os sinais já existentes e/ou a falta deles foram registrados por meio de anotações nas plantas baixas e em fotografias (Figura 5). Com base nesse levantamento, a equipe organizou e transferiu todos os dados em planilhas de Excel, o que possibilitou a identificação e o planejamento das sinalizações necessárias em cada uma das áreas do hospital. 


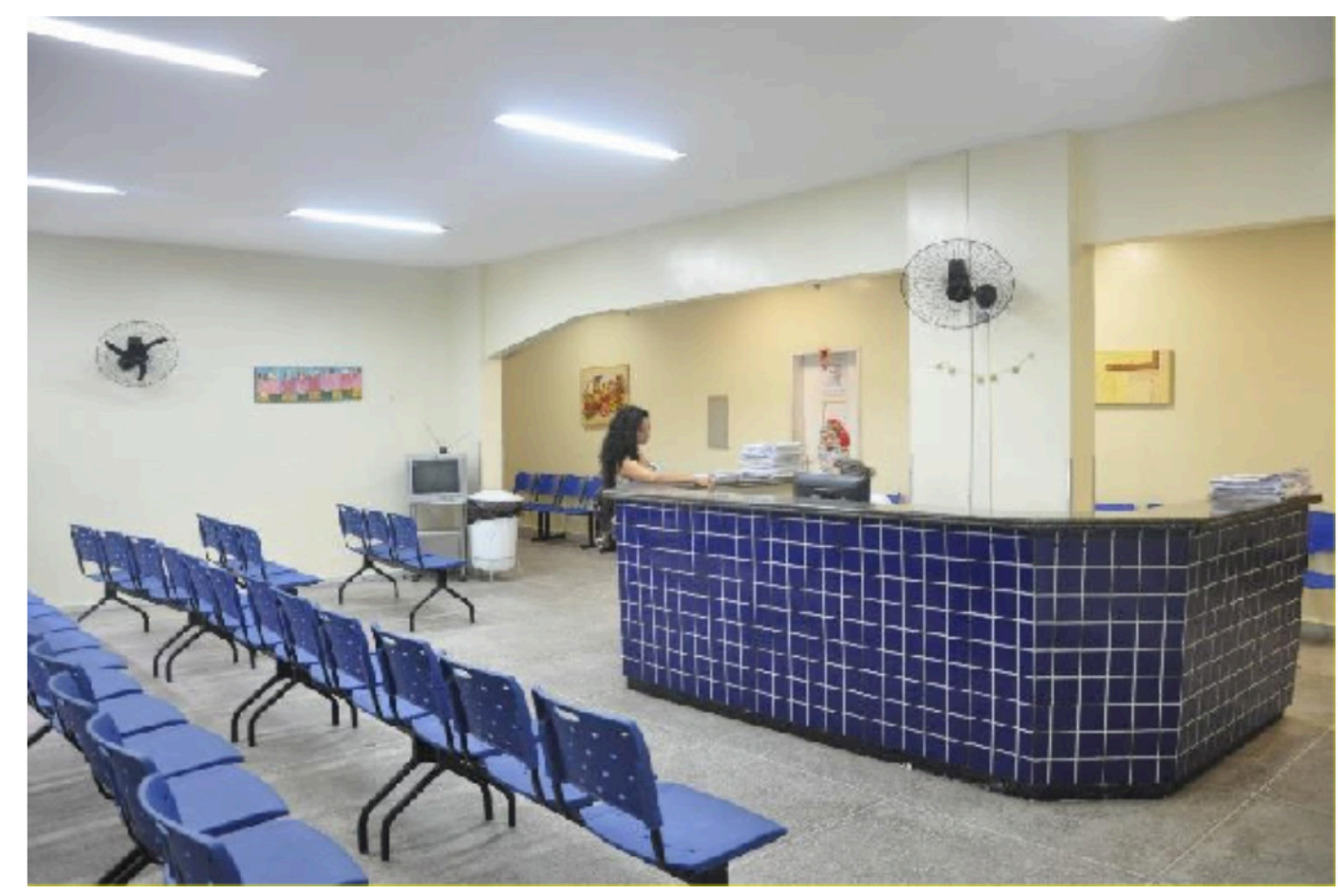

Figura 5 - Registro fotográfico de um dos balcões de recepção dos ambulatórios especializados sem identificação Fonte: Unidade de Comunicação Social do HUWC.

- Realização de visitas técnicas

No estágio final do mapeamento de sinais, iniciaram-se os contatos para agendamento de visitas técnicas a unidades hospitalares existentes no Ceará com o objetivo de auxiliar a equipe do projeto com referências de especificações técnicas de materiais para sinais internos e externos e recomendações para a gestão da sinalização. A equipe definiu, em alinhamento com o GT de Sinalização, três perfis de hospitais: um federal, um estadual e um particular, todos localizados no Ceará.

Para a escolha do hospital federal, diferentes aspectos foram levados em consideração: apresentar um modelo de organização parecido com o do HUWC, ou seja, em rede e com atuação em vários estados da Federação, e trabalhar a questão da acessibilidade, com espaços adaptados a pessoas com limitações de mobilidade.

No caso da unidade estadual, levou-se em consideração o fato de o hospital fazer parte de uma rede com sistema de sinalização padronizado, com modelo assistencial semelhante ao do Hospital Universitário
Walter Cantídio e atuação no interior do Estado. Para o hospital particular, foi definido que seria de uma rede nacional de referência e que apresentasse padrões gráficos em conformidade com o manual de sinalização da matriz.

\section{Desenvolvimento}

Esta etapa inclui o projeto de sinalização, o processo licitatório, a validação do conteúdo e o fechamento do manual de sinalização e ambientação do HUWC.

\section{Projeto de sinalização}

Esta etapa é dividida em dois pontos principais: a construção do conceito gráfico e a definição dos elementos de sinalização.

Com base no manual de identidade visual do Hospital Universitário Walter Cantídio (disponível em: <http://www. ebserh.gov.br/documents/214604/1459953/ Manual- de-Identidade-Visual-HUWC.pdf/ a5fb5a18-e302-4081-a577-a27505648141>) e nos estudos desenvolvidos pelo grupo 
de alunos da disciplina de Sinalética do Curso de Design da UFC. Ainda em 2016, a pesquisadora entrou em contato com a coordenadora do curso de Design para uma parceria quando da primeira tentativa de se construir um projeto de sinalização para o HUWC. A partir desse contato, uma disciplina optativa sobre sinalização foi ofertada, tendo como trabalho final o conceito gráfico inicial do projeto de sinalização do HUWC. Esse trabalho, desenvolvido pelos cinco alunos concludentes da disciplina, foi aproveitado na concepção do manual.

Assim como nas visitas ao HUWC e aos demais hospitais e, por fim, na revisão de literatura, a equipe desenvolveu a concepção gráfica do projeto de sinalização do $H U$, com definição de tipografia, cores, pictogramas, setas, disposição dos elementos gráficos e materiais usados.

Os elementos de sinalização foram desenvolvidos dando espaço à acessibilidade e ao uso de novas tecnologias, principalmente na integração entre os blocos do hospital, assim como respeitando a legislação vigente sobre sinalização hospitalar. Por exemplo, a Norma Brasileira 13.434, da Associação Brasileira de Normas Técnicas (ABNT), que orienta sobre sinalização de segurança contra incêndio e pânico, foi considerada no projeto.

Dessa forma, todas as especificações dos elementos foram finalmente organizadas e detalhadas no Sistema de Gerenciamento de Conteúdo de Sinalização. Nesse sistema, cada planta baixa está associada a uma planilha específica contendo todas as informações sobre a definição dos elementos necessários para sinalização.

\section{Processo licitatório}

Com a definição dos elementos de sinalização, foi possível concluir a reunião de documentos para dar início ao processo licitatório de contratação de fornecedor para executar o projeto de sinalização do Hospital Universitário Walter Cantídio. No dia 7 de maio de 2018, todos os documentos foram entregues e foi aberto o processo sob o número 23533.000554/2018-21 no Sistema de Informações Gerenciais da Ebserh. O apoio da Divisão Administrativa Financeira, do Setor de Planejamento e da Unidade de Licitações foi fundamental para a documentação ficar pronta em tempo hábil.

De acordo com a Instrução Normativa (IN) $n^{\circ}$ 05, de 25 de maio de 2017, que é a norma usada pela Gerência Administrativa do Complexo Hospitalar da UFC para contratação de serviços, a fim de dar início ao processo licitatório, é preciso apresentar os seguintes documentos: memorando de abertura do processo licitatório, documentos de formalização da demanda e estudos preliminares (que justificam a abertura do processo licitatório), mapa de riscos (que listam os riscos inerentes a esse tipo de contratação) e rmo de referência (que detalha o objeto a ser contratado, com todas as obrigações de contratante e contratado, a planilha com os sinais a serem produzidos, etc.). Ao todo, o processo, até o dia 23 de novembro de 2018, já contabilizava 352 páginas (Figura 6). 


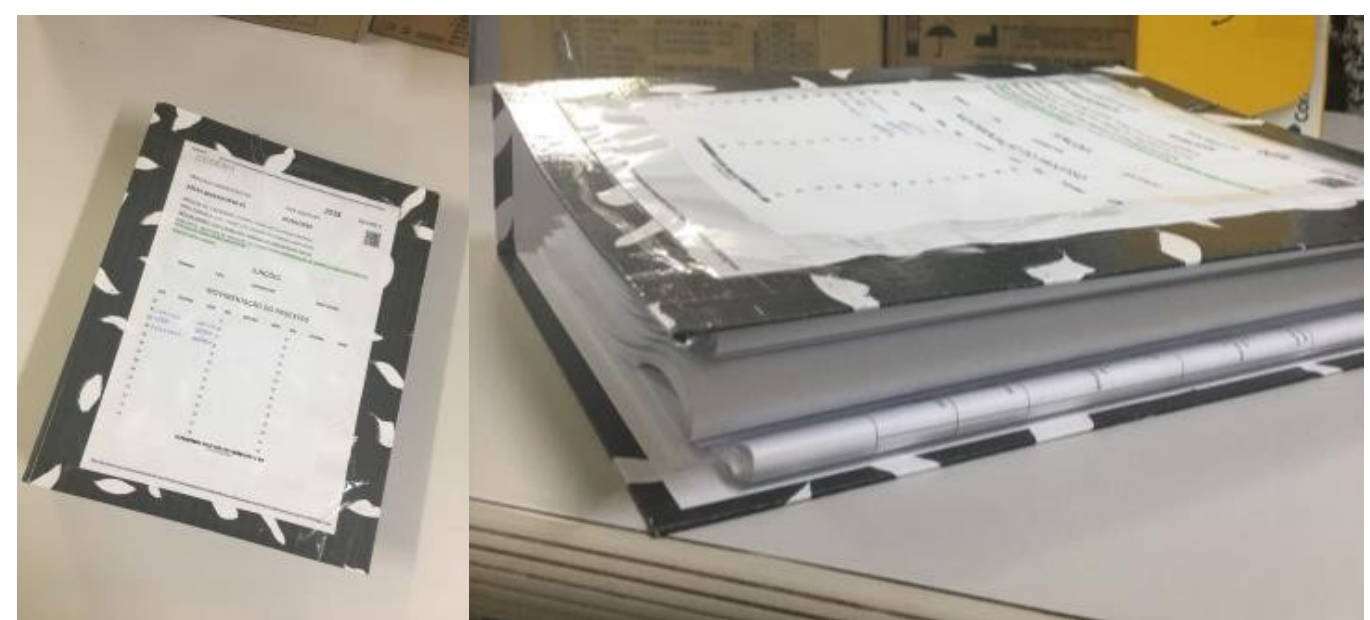

Figura 6 - Processo licitatório físico

Fonte: Autoria própria.

Outra dificuldade encontrada foi com relação à participação da Maternidade-Escola Assis Chateaubriand (MEAC) no processo. A ideia inicial era contemplar também a MEAC, mas o recurso autorizado não é suficiente sequer para o HUWC. Outro ponto importante que contribuiu para a decisão de tramitar o processo somente com o hospital foi o prazo de execução do recurso, ou seja, até dezembro de 2018. Com a inclusão da maternidade, seria necessário desenvolver um projeto de sinalização para a instituição também, o que certamente extrapolaria o referido prazo. É bem verdade que isso não é a melhor solução, tendo em vista se tratar de unidades de um mesmo complexo hospitalar, mas essa se configurou como a única opção para não perder o recurso destinado.

\section{Validação do conteúdo}

Na última fase do projeto, o conteúdo e o conceito gráfico dos sinais foram validados pela comunidade hospitalar. Como há 2.704 colaboradores no Hospital Universitário, optou-se por validá-los em grupos já institucionalizados, como os colegiados gestores e as reuniões de coordenação de equipes. Essa fase foi importante para dar segurança à qualidade das informações reunidas, principalmente porque o HUWC passa por transformações constantes e foi coletado um volume muito grande de dados ao longo de todo o processo metodológico.

Foram realizadas reuniões com esses grupos. $O$ projeto também foi validado com o GT de Sinalização e com a direção do Hospital Universitário Walter Cantídio. A partir de agendamento prévio e contando com registro por meio de atas individualizadas, as reuniões foram conduzidas pela equipe da Unidade de Comunicação Social. Cada encontro foi dividido em quatro momentos básicos: contextualização do projeto; resumo dos resultados alcançados; aplicações de elementos de sinalização em imagens reais; e validação da planta baixa e dos elementos gráficos da respectiva área. As sugestões foram analisadas e validadas em conjunto, com decisão colegiada registrada em ata. Depois das reuniões, as mudanças foram feitas nas plantas baixas e no projeto gráfico em programas específicos de computador.

\section{Fechamento do manual de sinalização e ambientação do hospital universitário walter cantídio}

Com as validações finalizadas, foi possível fechar o manual de sinalização e ambientação do Hospital Universitário Walter Cantídio. O documento foi elaborado pela equipe da Unidade de Comunicação Social, com coordenação da jornalista responsável 
pelo setor e operacionalização de uma assistente administrativa e uma profissional terceirizada com conhecimento em Design. Foi feito um grande esforço para conciliar as demandas da unidade ao trabalho de fechamento do manual.

\section{Execução}

Esta é a última etapa da metodologia. Trata-se da execução do projeto de sinalização pelo fornecedor vencedor do processo de licitação em curso e da avaliação do projeto, depois de executado, pela comunidade hospitalar por meio de instrumentos como pesquisa de satisfação. É uma etapa a ser aprofundada em estudos futuros.

\section{RESULTADOS E DISCUSSÕES}

\section{Rede de apoio construída e fortalecida}

Tanto a direção do Hospital Universitário Walter Cantídio como o Grupo de Trabalho de Sinalização foram decisivos na condução do projeto no HUWC em relação a sugestões, validações e outras tomadas de decisão. Composto por representantes de áreas estratégicas - Comunicação, Infraestrutura, Atenção à Saúde, Segurança do Paciente, Clínica Médica, Hotelaria, Orçamentos e Finanças, Segurança do Trabalho e Ensino e Pesquisa - nomeados em portaria específica pela Superintendência, o GT atuou nas questões técnicas, municiando o grupo operacional do projeto com exigências do ponto de vista regulatório e colaborando, a partir da própria experiência, com a dinâmica hospitalar para a correta sinalização do HU.

O Setor de Infraestrutura (SIF), o qual inclui a Arquitetura, também foi contatado. Mas o SIF alegou não dispor de tempo nem de mão de obra para ajudar, tendo em vista uma lista expressiva de demandas reprimidas relacionadas a obras estruturais no HUWC.
O tema foi levado à direção do HUWC, que mais uma vez apoiou o projeto e autorizou a participação parcial da arquiteta e a liberação total das plantas baixas. Como, ainda assim, o tempo dedicado pela profissional de Arquitetura ao projeto não era suficiente, partiu-se em busca de apoio externo.

Pelo fato de o HUWC ser parte de uma universidade com cursos de Design e Arquitetura na sua oferta acadêmica, conseguiu-se estabelecer parcerias com as respectivas coordenações, o que possibilitou que alunos das duas áreas cumprissem estágio curricular obrigatório no HUWC e que um professor doutor em Design e especialista em sinalização ajudasse na coordenação técnica do projeto no hospital. Com o apoio da gestão, a Unidade de Comunicação Social conseguiu também que o hospital contratasse, via empresa terceirizada, uma profissional com conhecimento em Design (no último semestre do curso pela UFC) para coordenar a concepção gráfica do projeto de sinalização.

A gestão também autorizou a liberação de mesa, cadeira e um computador com softwares de edição de imagem (Illustrator, Indesign e Photoshop) para a colaboradora terceirizada. A UCS já contava com maquinário semelhante para a estagiária de Design. Foram liberados, ainda, a pedido da Comunicação, mesa, cadeira e computador com Autocad (software para desenhos arquitetônicos) para o estagiário de Arquitetura. A existência de uma impressora com impressão colorida nos formatos A4 $(21 \mathrm{~cm} \times 29,7 \mathrm{~cm})$ e A3 $(29,7 \mathrm{~cm} \times 42 \mathrm{~cm})$ na Comunicação, para atendimento das demandas diárias da unidade, também ajudou substancialmente no processo de produção das peças gráficas e dos demais documentos do projeto de sinalização.

Sobre a busca de apoio financeiro via emenda parlamentar, o contato inicial foi feito com o assessor responsável pela coordenação das emendas da deputada federal, o qual, após uma visita ao HU, sinalizou possibilidade de destinação de 
$\mathrm{R} \$ 250$ mil para o projeto em forma de emenda individual (Figura 7a). Os deputados podem destinar parte dos recursos do orçamento da União para compromissos políticos assumidos durante o mandato com municípios, estados e até mesmo instituições. A emenda individual é aquela de autoria do próprio deputado.

A direção do HUWC custeou duas idas a Brasília em outubro de 2017. Na comitiva, o superintendente do Complexo Hospitalar da UFC; a gerente de Atenção à Saúde do HUWC; e esta pesquisadora, na função de chefe da Unidade de Comunicação Social do hospital. Nas viagens, os gestores visitaram os gabinetes dos 22 deputados da bancada federal e dos 3 senadores do Ceará e fizeram a defesa da proposta. Meses depois, o valor foi confirmado como autorizado pela equipe da deputada federal e transferido para o orçamento do hospital (Figura 7).

CONGRESSO NACIONAL

COMISSÃO MIISTA DE PLANOS, ORÇAMENTOS E FISCALIZAÇÃO

Data: $20 / 10 / 2017$

EMENDAS AO PLN 0020 / 2017 - LOA

Hora: $21: 16$

Página: 4703 de 8350

\section{ESPELHO DE EMENDA DE APROPRIAÇÃO DE DESPESA}

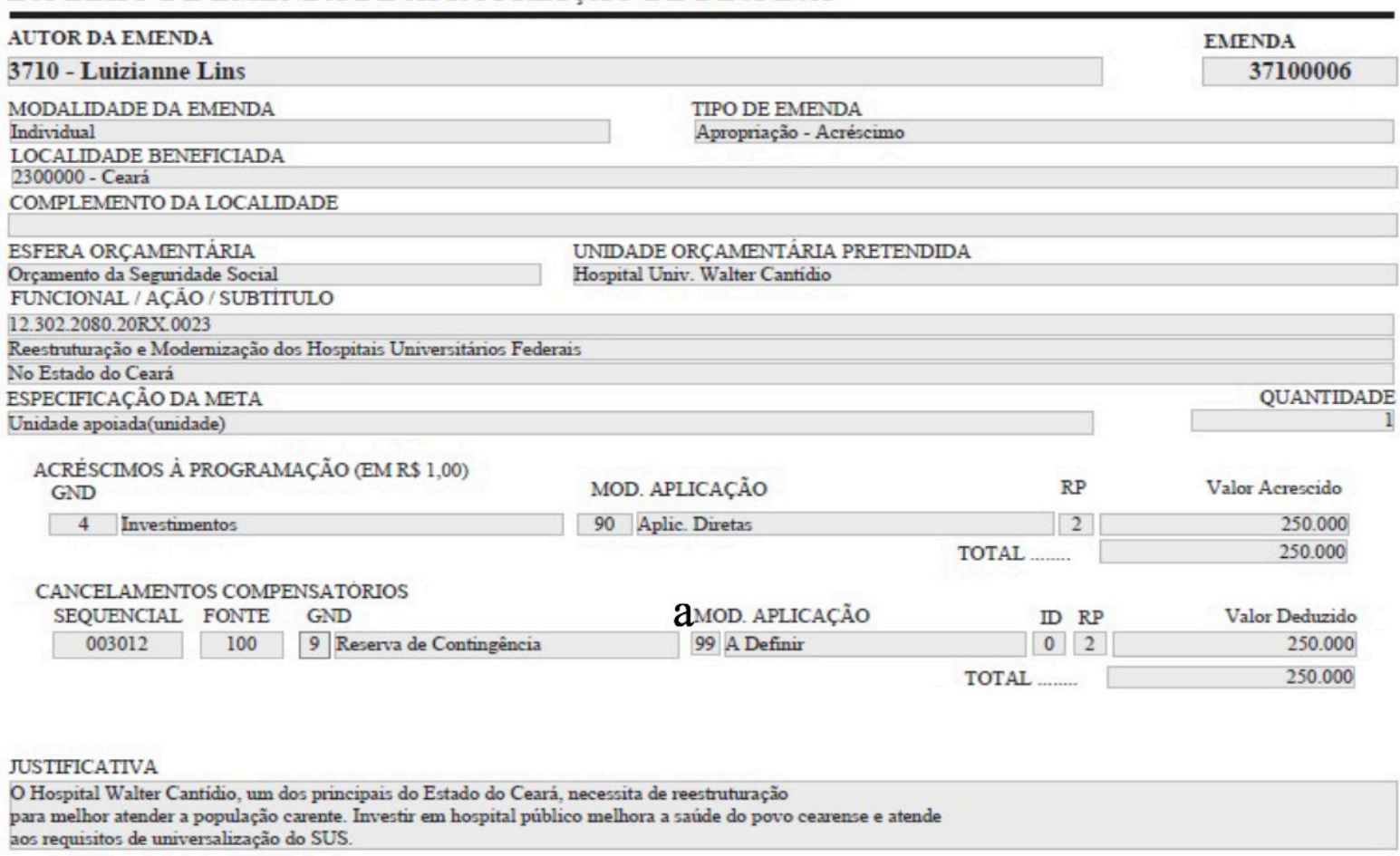

Figura 7 - Evidências de destinação de recurso para financiar o projeto de sinalização do HUWC: a) Espelho da emenda parlamentar individual destinada ao HUWC; b) Confirmação da inclusão do recurso de R\$250 mil no orçamento do hospital Fonte: Sistema de emendas parlamentares do Congresso Nacional e Sistema de acompanhamento orçamentário do HUWC.

\section{Diagnóstico sistêmico}

O núcleo de Arquitetura do projeto atualizou 15 plantas baixas e criou uma do Ambulatório de Oftalmologia, o que possibilitou ter um dimensionamento real da área construída, além da largura e do comprimento dos elementos internos e externos, já que, na planta baixa, consegue-se visualizar o ambiente como se estivesse olhando de cima, sem o telhado (MARKUN, 2014).

O material coletado nas visitas do núcleo de Comunicação do projeto aos setores do 
hospital gerou um conjunto de planilhas com as informações distribuídas nas seguintes colunas: número de identificação (número do sinal na planta baixa), descrição da foto (identificação da imagem), local de inserção (onde o sinal está no ambiente), conteúdo do sinal (o que está escrito nele), tipo de sinal (placa de porta, quadro de aviso etc), permissões de acesso (que pessoas estão autorizadas a acessar o espaço) e observações (anotações outras, como a necessidade de um novo sinal).

A partir do diagnóstico feito, a equipe voltou as 16 plantas baixas para marcar, em cada uma, que sinais existentes deveriam permanecer e quais e onde deveriam ser criados novos, um dos momentos mais delicados e trabalhosos do projeto. Ao consultar as plantas baixas, a equipe identificou que alguns espaços já não correspondiam à realidade representada no papel, mesmo esse comparativo tendo sido feito cerca de um mês depois da atualização das plantas baixas.

Isso só comprovou que as mudanças estruturais no Hospital Universitário Walter Cantídio aconteciam à revelia da gestão. Em função disso, houve bastante retrabaIho, com novas visitas e diagnósticos das áreas modificadas. Cada círculo colorido na Figura 8 representa um sinal. Isso foi feito em todas as plantas baixas.

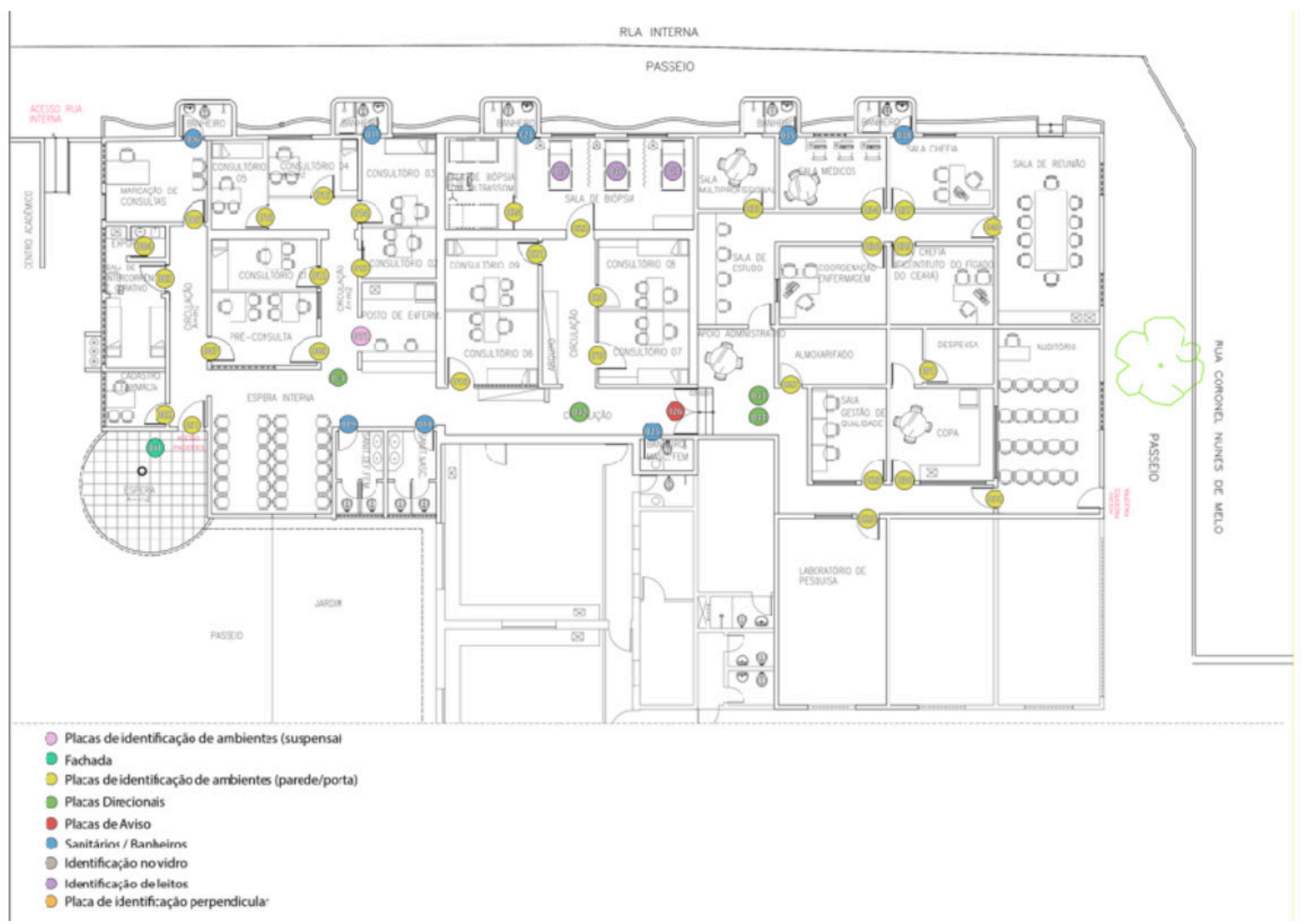

Figura 8 - Mapeamento de sinais na planta baixa do ambulatório do transplante hepático Fonte: Unidade de Comunicação Social do HUWC. 
Por ser um hospital da década de 1950, com uma arquitetura marcada pelo modelo pavilhonar (AMORA, 2014), com longos corredores e poucos pavimentos, e não ter crescido a partir de um plano diretor estruturado e respeitado, o Hospital Universitário Walter Cantídio apresenta hoje uma organização extremamente descentralizada, sem padronização e difícil de entender, mais ainda de sinalizar. Mora, Oats e Marziano (2014) defendem que o crescimento não planejado dos hospitais dificulta a orientação e a realização de wayfinding nessas unidades.

De acordo com Mora, Oats e Marziano (2014) e Adams (2017), chegar a um destino dentro de um hospital contribui para a redução do estresse e da frustração do usuário, que já não se encontra num estado emocional favorável, seja porque está doente ou acompanha alguém assim ou, ainda, por estar na investigação de uma doença mais grave. Ademais, aumenta a confiança no trabalho feito pela unidade de saúde. Por essa razão, os autores afirmam que é necessário um "desenho saudável" dos espaços hospitalares, que considere, entre outros pontos, uma sinalização que oriente as pessoas.

As visitas técnicas, por sua vez, deram importantes contribuições aos tipos, formatos, tamanhos e materiais das placas de sinalização internas e externas usadas no projeto de sinalização do Hospital Universitário Walter Cantídio. Além disso, a troca de experiências com os hospitais foi determinante para a delimitação da gestão do projeto, principalmente com relação às definições de responsabilidades dos agentes envolvidos, como os profissionais de Comunicação e Arquitetura.

O hospital federal apresenta sinalização padronizada, de modo que mudanças estruturais precisam de autorização prévia da equipe de Arquitetura. Os espaços são separados por cores, que aparecem nas placas de identificação de ambientes. No hospital há, basicamente, três tipos de placas: ambiente, sala e espaços comuns (copa e banheiro). As placas são de PVC ou alumínio adesivado. Alguns exemplos de placas estão apresentados na Figura 9.

Cabe salientar que há um totem digital no espaço de marcação de procedimentos. Ao se identificar e informar sua necessidade no totem, o usuário é orientado a procurar a recepção pela cor das cadeiras. Sendo assim, apesar de ter a acessibilidade como centro da sua proposta arquitetônica, a sinalização não é acessível. Nesse contexto, Bonfanti et al. (2017) lembram que as pessoas com deficiência não devem ser esquecidas em projetos de sinalização. 


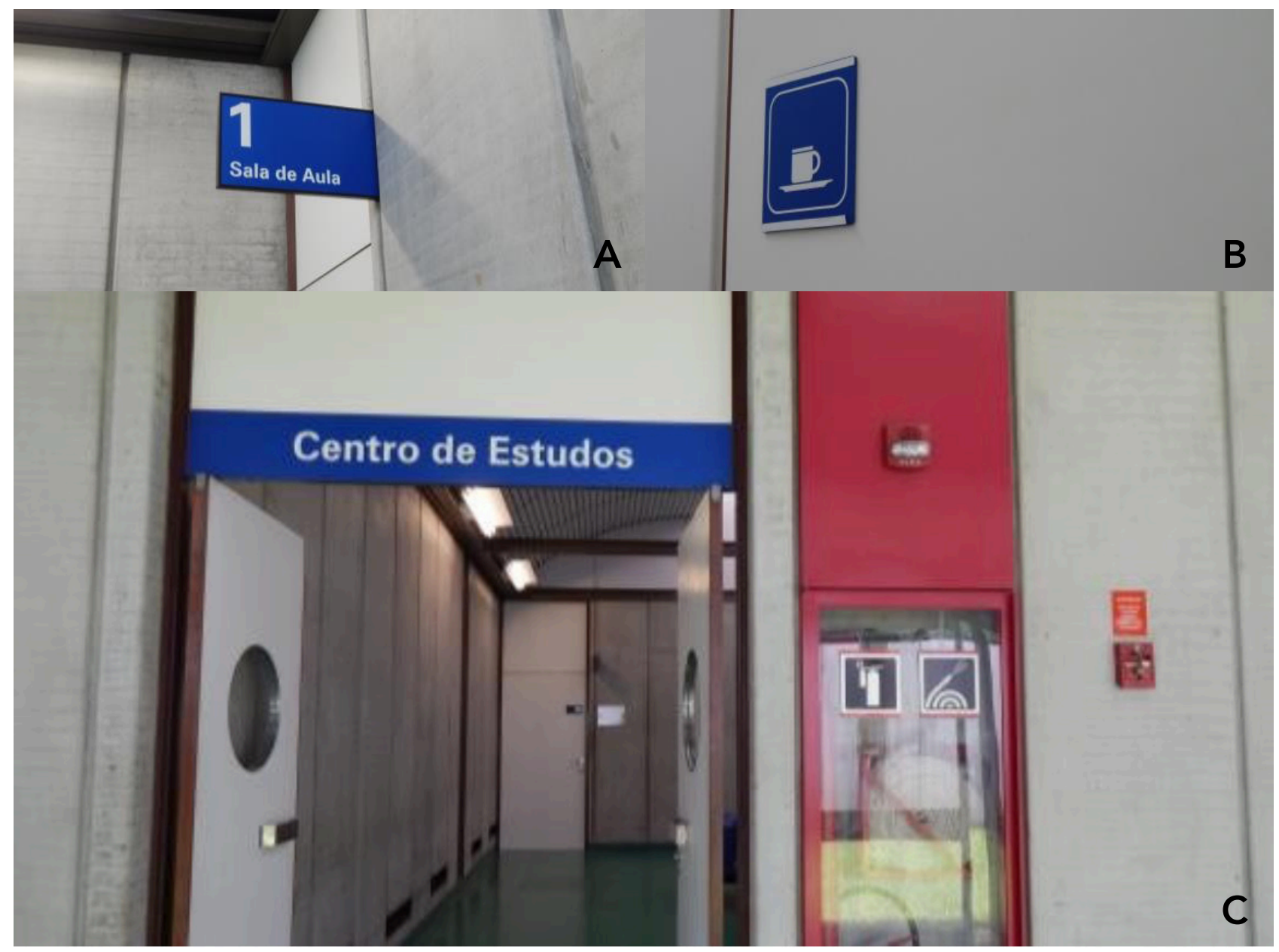

Figura 9 - Sinalização do hospital federal: a) Placa perpendicular de porta; b) Placa de espaço comum; c) Placa de identificação de ambiente

Fonte: Autoria própria.

A área externa do hospital estadual conta com fachada identificada em letreiro com revestimento ACM (alumínio composto) e estacionamento com vagas especiais sinalizadas. A área também é acessível, com rampas e piso tátil até a entrada principal do hospital. Porém, a acessibilidade perde força nas áreas internas - apesar de haver banheiros e elevadores adaptados - e desaparece na sinalização (Figura 10). Internamente, há placas para identificar salas e setores. Os materiais usados são alumínio ou PVC adesivado, a fim de facilitar a higienização.

De acordo com Imrie e Hall (2004), quando os projetos dão espaço a soluções acessíveis, há uma tendência de priorizar o usuário cadeirante em detrimento dos usuários com demais deficiências. Os idosos também estão entre os esquecidos. Isso constitui um cenário grave, pois Marquez et al. (2017) afirmam que, com o envelhecimento, as pessoas passam a apresentar maior dificuldade de orientação e deslocamento em busca de um determinado destino, consequências das limitações da própria idade.

No que tange à identificação, há um rigoroso padrão, que abrange desde crachás de visitantes até placas de cuidados com a segurança dos pacientes no leito hospitalar. A gestão dessa padronização é do Núcleo de Qualidade de Gerência de Risco, com fiscalização diária. Toda semana uma comitiva de gestores visita as unidades para, entre outros objetivos, reforçar esse cuidado na "caminhada da segurança". Há controlistas de acesso em pontos estratégicos do hospital. São terceirizados que orientam as pessoas que precisam de ajuda para localizar determinado setor. Na Figura 10, registros da sinalização do hospital. 


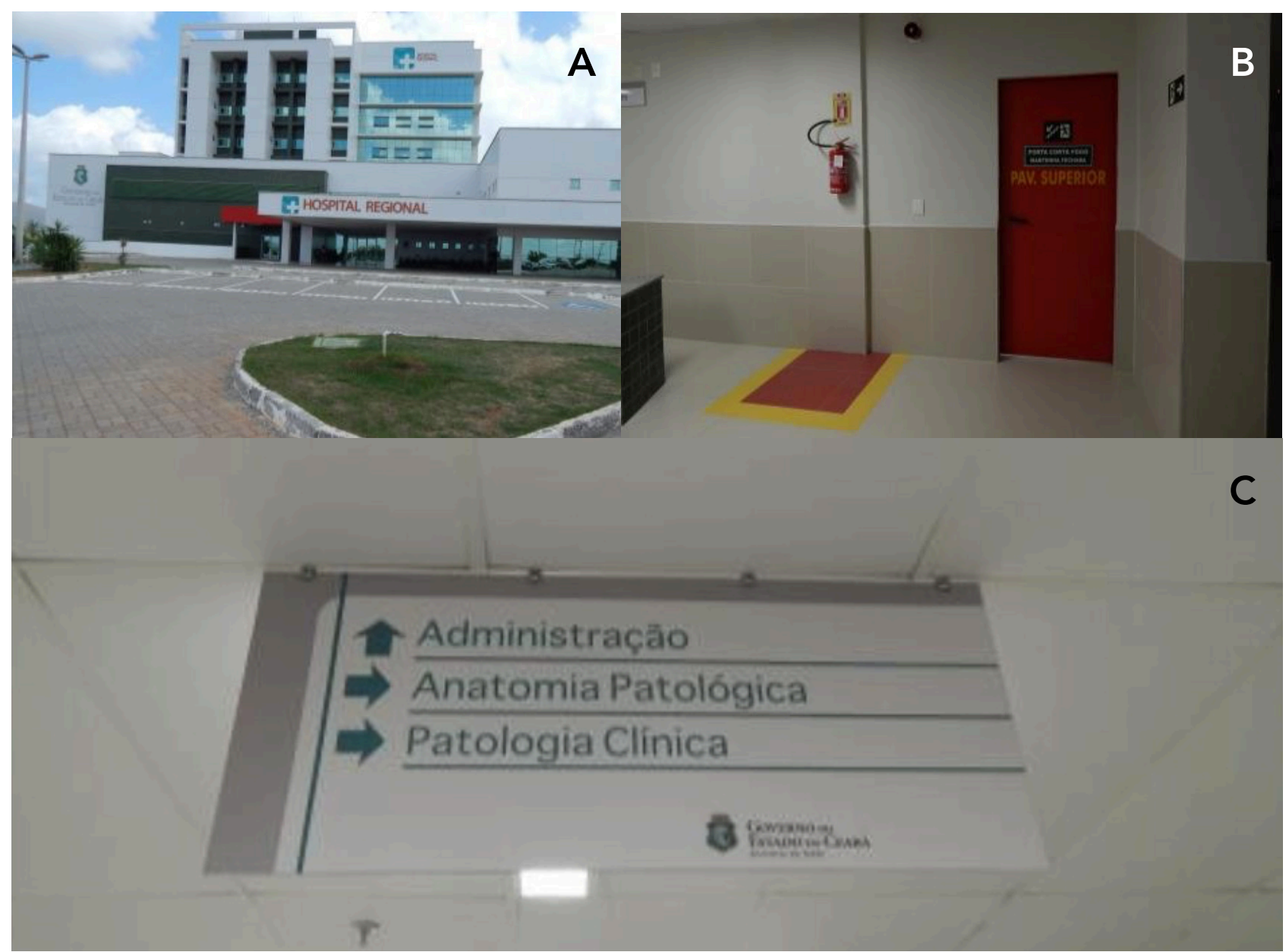

Figura 10 - Sinalização do hospital estadual: a) Fachada do hospital com estacionamento sinalizado; b) Sinalização de segurança contra incêndios; c) Placa direcional

Fonte: Autoria própria.

No hospital particular, há padronização de cores e pictogramas, assim como de tipos e tons de piso, granito, parede e madeira, conforme manual de sinalização. Minimalistas, os pictogramas são divididos em categorias (exames de imagem, laboratório, leitos, etc.). O hospital possui, ainda, um manual de padronização de desenho infantil (Figura 12b). Alvarez (2014), Neves et al. (2016) e Joy Lo, Yien e Chen (2016) defendem o uso de pictogramas - sinais gráficos - para facilitar a comunicação no ambiente hospitalar. Além de reduzirem a quantidade de texto em sinais, eles ajudam a "traduzir" termos técnicos.

Em geral, no hospital os sinais têm tradução para o inglês para tornar a sinalização acessível a estrangeiros. Isso é relevante, dado que Schuster, Elroy e Elmakais (2017) sustentam que a falta de acessibilidade linguística da sinalização pode prejudicar a saúde do usuário, contribuir para a alienação e o isolamento, bem como aumentar o nível de incompreensão de informações, instruções e proibições dentro da unidade hospitalar.

Tudo que tem relação com a sinalização passa pela Engenharia/Arquitetura e pela Comunicação. A primeira faz o projeto de acordo com o manual de sinalização. A segunda valida o layout das peças. Se uma unidade precisa fazer alguma alteração na sinalização, é esta unidade que se responsabiliza pelos custos dessa mudança. Segundo uma arquiteta do hospital, isso torna os setores mais conscientes no uso dos recursos.

Internamente, os materiais utilizados são PVC com adesivo vinílico. Na parte externa, predomina $\circ \mathrm{ACM}$, pelas características de resistência e durabilidade. Os quadros de aviso são de PVC adesivado com "bolsos" 
de acrílico nos formatos $A 4$ e $A 3$, o que permite limpeza e limita a quantidade de informações dispostas, contribuindo para a organização (Figura 11a). Há cuidado com o acabamento das peças, que, no geral, são boleadas, imprimindo sofisticação.
Além disso, faz-se uso de placas do tipo "bandeira" nas portas, o que facilita a identificação das áreas, especialmente em longos corredores (Figura 11c). A manutenção da sinalização deixa o sistema sempre atualizado e padronizado.

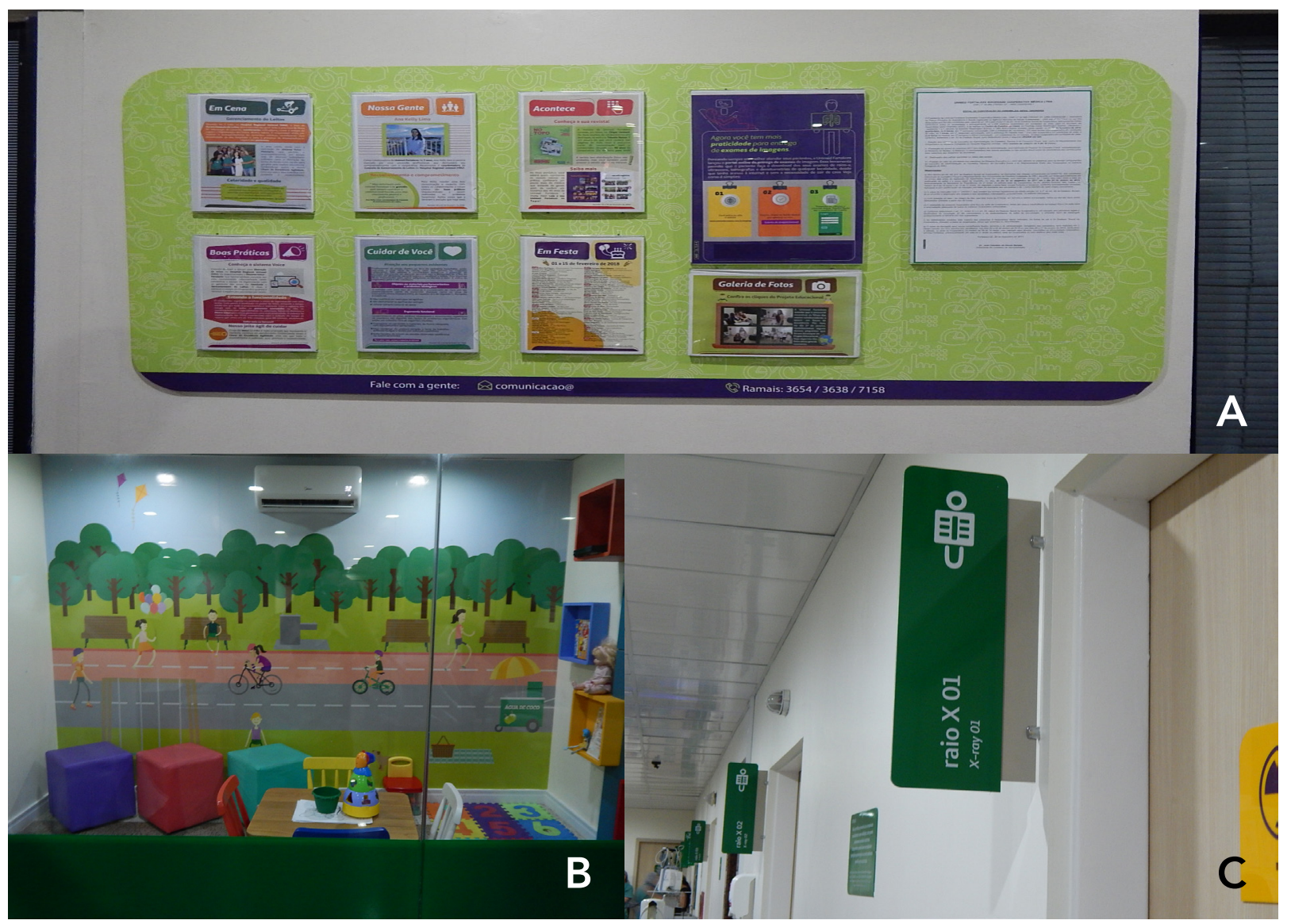

Figura 11 - Sinalização do hospital particular: a) Quadro de aviso; b) Espaço lounge infantil; c) Placa perpendicular de porta Fonte: Autoria própria.

\section{O projeto de sinalização}

Neste estágio, foram definidos todos os elementos de sinalização, com seus tipos, tamanhos, formatos, materiais, pictogramas e localização nas plantas baixas. $O$ projeto de sinalização proposto para o Hospital Universitário Walter Cantídio conta com 146 categorias de elementos, assim divididas: comunicação (59), segurança do trabalhador e do paciente (60) e hotelaria (27).

São placas internas e especiais; quadros informativos; totens físico e digital; adesivos com QR Code; mapa tátil; placas em braile; bolsões de acrílico; faixas de piso e parede; adesivos de porta e parede; fachadas; cone e cavalete; e demarcação de piso e parede com pintura. De acordo com Leonard, Verster e Coetzee (2014), a utilização de faixas coloridas pintadas ao longo dos corredores torna mais acolhedora e eficaz a sinalização num hospital. As 146 categorias geraram 19.177 elementos de sinalização, conforme termo de referência do processo licitatório.

A proposta prevê, nas entradas principais, o uso de totens digitais com Vlibras 
- Plataforma VLibras. Disponível em: http:// www.vlibras.gov.br - sistema responsável por traduzir conteúdos digitais para a Língua Brasileira de Sinais (Libras), tornando os equipamentos acessíveis a deficientes auditivos. Esse sistema digital de sinalização foi desenvolvido em parceria com o Laboratório de Inovação Tecnológica em Saúde da Universidade Federal do Rio Grande do Norte (LAIS-UFRN). O projeto de sinalização inclui, ainda, mapas táteis, que auxiliam deficientes visuais ou pessoas com baixa visão sobre os trajetos mais acessíveis. A proposta engloba também adesivos com QR Code com informações complementares à sinalização tradicional.

Sob o ponto de vista de inovação, há autores que apontam a sinalização digital como importante ferramenta de apoio no processo de wayfinding. Yanyu, Ketai e Ailan (2013) afirmam que a sinalização digital tem recebido fortes investimentos de tecnologia de informação nos últimos anos e contribuído muito para a melhoria da gestão e dos serviços hospitalares. Bonfanti et al. (2017) citam sites, dispositivos móveis, smartphones e aplicativos para download como alguns dos recursos utilizados para facilitar a navegação. Segundo Fellner, Huang e Gartner (2017), técnicas diferentes podem ser usadas para comunicar informações de rota/navegação, como mapas, instruções verbais, 3D, realidade aumentada e háptica.

Outra particularidade deste projeto é o respeito à legislação vigente sobre sinalização hospitalar. Por exemplo, a Norma Brasileira 13.434, da Associação Brasileira de Normas Técnicas (ABNT), que orienta sobre sinalização de segurança contra incêndio e pânico, é um dos regulamentos contemplados neste trabalho. Conforme Proulx (2002), o estresse, o curto espaço de tempo para evacuar o ambiente e o nervosismo comprometem a orientação e o direcionamento em hospitais durante situações de incêndio. É importante, portanto, fornecer informações para acelerar o tempo de evacuação e o comportamento eficaz e eficiente nessa fuga (GWYNNE; GALEA, 2001; PROULX; SIME, 1991).

As especificações dos elementos estão organizadas e detalhadas no Sistema de Gerenciamento de Conteúdo de Sinalização. Cada planta baixa está associada a uma planiIha específica (Figura 12), com colunas assim divididas: região (entrada, ambulatório $X$, enfermaria $Y$, etc.), número de identificação na planta baixa, local de inserção do sinal (no guichê $X$, acima do vidro, na porta do banheiro feminino, etc.), conteúdo do sinal, categoria (placa de porta, placa bandeira, etc.), pictograma, cor do sinal e observações. 


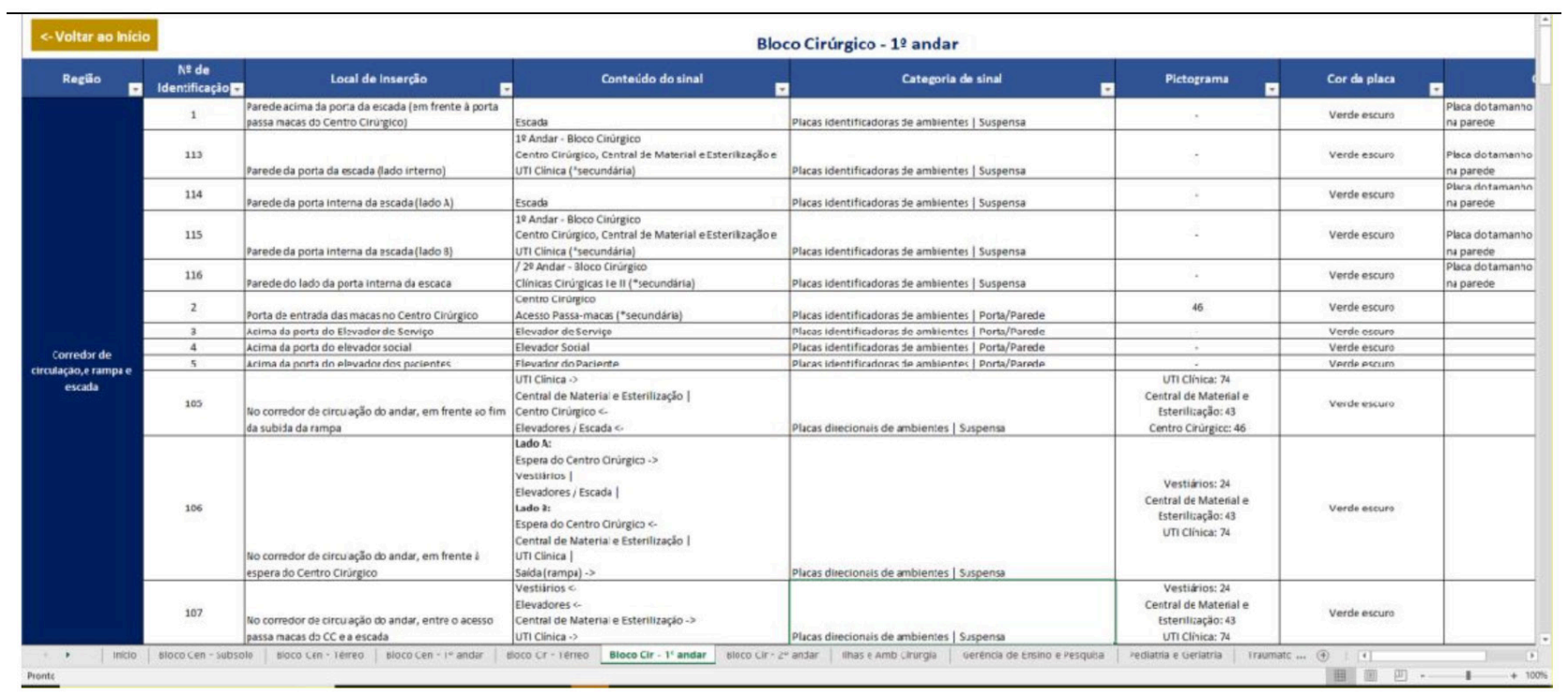

Figura 12 - Conjunto de planilhas de sinalização interna

Fonte: Sistema de Gerenciamento de Conteúdo de Sinalização.

Esse modelo de organização evita a reprodução gráfica de um grande volume de sinais iguais, traduz o projeto para fornecedores e interessados em geral e permite o controle e a atualização permanente das informações do projeto de sinalização. As planilhas do sistema estão sob a gestão da Unidade de Comunicação Social, responsável pela gestão do projeto.

\section{Licitação em fase final}

O processo licitatório está na fase final, em análise no Setor Jurídico, para posterior disponibilização para pregão eletrônico.

\section{Validação de conteúdo colegiada}

Foram realizadas 40 reuniões (Figura 13) com a participação de diversos membros do hospital. Um dos principais ganhos conquistados nessa fase foi a capacidade de os grupos, dos menores aos maiores, chegarem a um consenso com relação a um sistema único de sinalização, tendo em vista os diversos perfis de participantes. Também se ganhou com a padronização de nomes de espaços comuns, como banheiros, copas, postos de enfermagem, depósitos de material de limpeza, salas de apoio acadêmico, etc. 


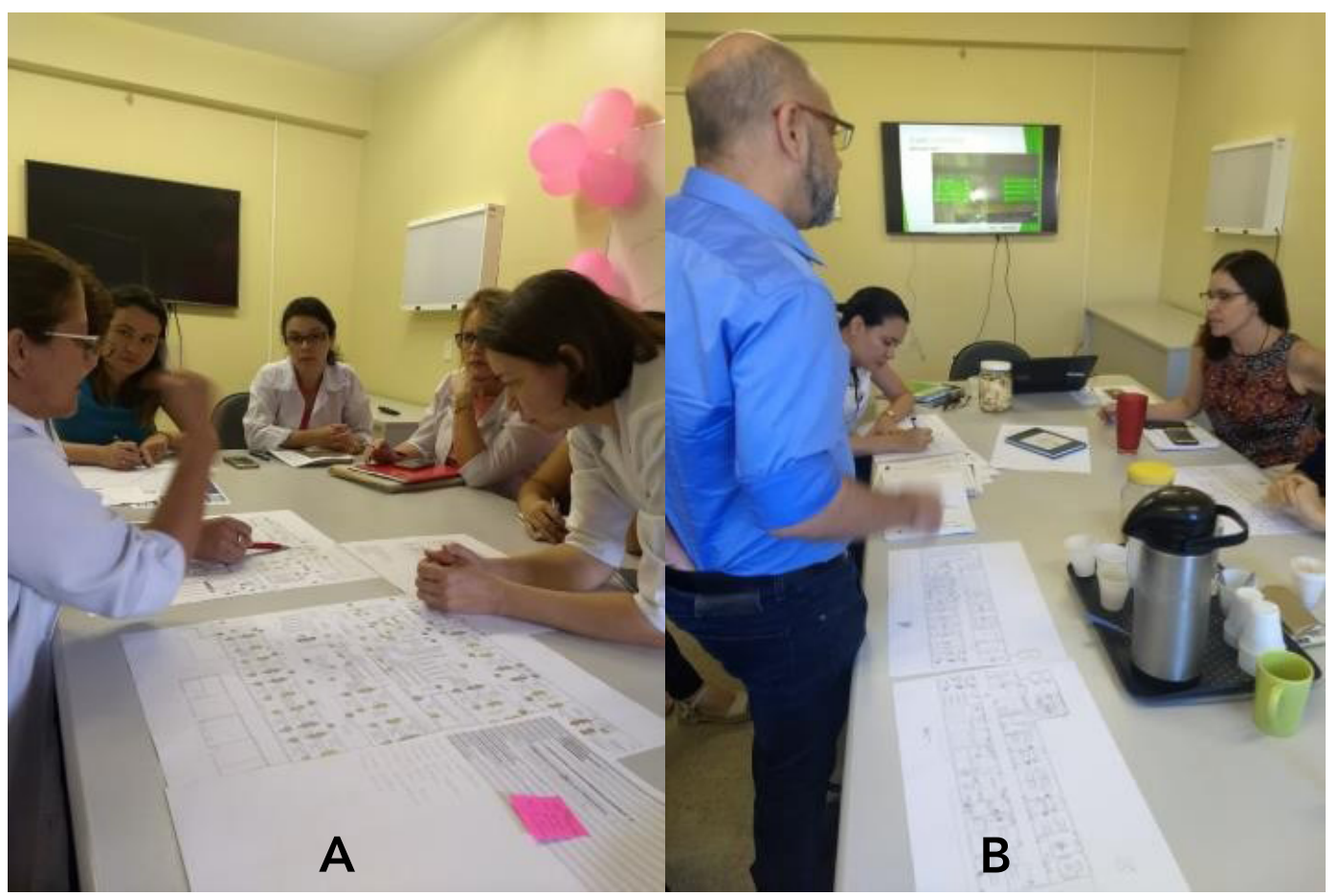

Figura 13 - Reuniões para validação do conteúdo: a) Reunião de validação do colegiado gestor dos ambulatórios; b) Reunião de coordenação da gerência de ensino e pesquisa

Fonte: Unidade de Comunicação Social do HUWC.

Scherer, Cattani e Silva (2017) e Borges e Silva (2015), inclusive, afirmam que o profissional de saúde, o paciente e qualquer outro usuário que circula e faz uso das informações existentes no ambiente precisam ser considerados nas metodologias de projetos de sinalização. Nesse viés, Reay et al. (2017) e Leonard, Verster e Coetzee (2014) descrevem metodologias de design participativo - envolvendo designers, profissionais de saúde e pacientes em algum estágio metodológico - e elencam benefícios dessa participação, como simplificação e padronização da sinalização.

De fato, foi interessante perceber a satisfação das pessoas por estarem participando do processo de construção do sistema e ouvir as sugestões oportunas dadas pelas equipes durante as reuniões. Segundo Leonard, Verster e Coetzee (2014), os funcionários se sentem satisfeitos de participar da construção de um sistema de sinalização. Entretanto, houve momentos de discussões mais pesadas, com desentendimentos e reclamações. Inclusive, algumas práticas equivocadas, como numeração descontínua de salas, foram mantidas, apesar das propostas de mudanças sugeridas.

Annemans et al. (2017) levantam a possibilidade de haver conflito entre o que é útil para o trabalho do designer, o que é relevante para o paciente e o que deseja o profissional de saúde. Por essa razão, acrescentam os autores, é preciso cautela na hora de inserir o usuário nesse processo. Short, Reay e Gilderdale (2017), por exemplo, sugerem o uso de protótipos para que as partes interessadas testem a proposta já tecnicamente construída.

\section{Manual fechado e em processo de registro autoral}

A publicação, que está em processo de registro no Escritório de Direitos Autorais da Biblioteca Nacional, conta com 124 páginas e é composta pelas seguintes seções: uma parte introdutória, com informações sobre o hospital, a metodologia usada para desenvolver o manual e o conceito gráfico do projeto; os macrossistemas comunicação, 
segurança do trabalhador e do paciente e hotelaria, com todas as especificações técnicas de seus respectivos sinais; e o sistema de gestão da sinalização, com explicações de como se dá a administração desse processo.

Por questão de segurança, as plantas baixas e as planilhas de gerenciamento de conteúdo estarão disponíveis apenas para o gestor do projeto. No caso do HUWC, com a Unidade de Comunicação Social. A capa e uma das primeiras páginas do manual podem ser observadas na Figura 14. O manual completo está disponível aqui: <https://pt.calameo.com/ read/0056660207fa33e5deeda $>$.
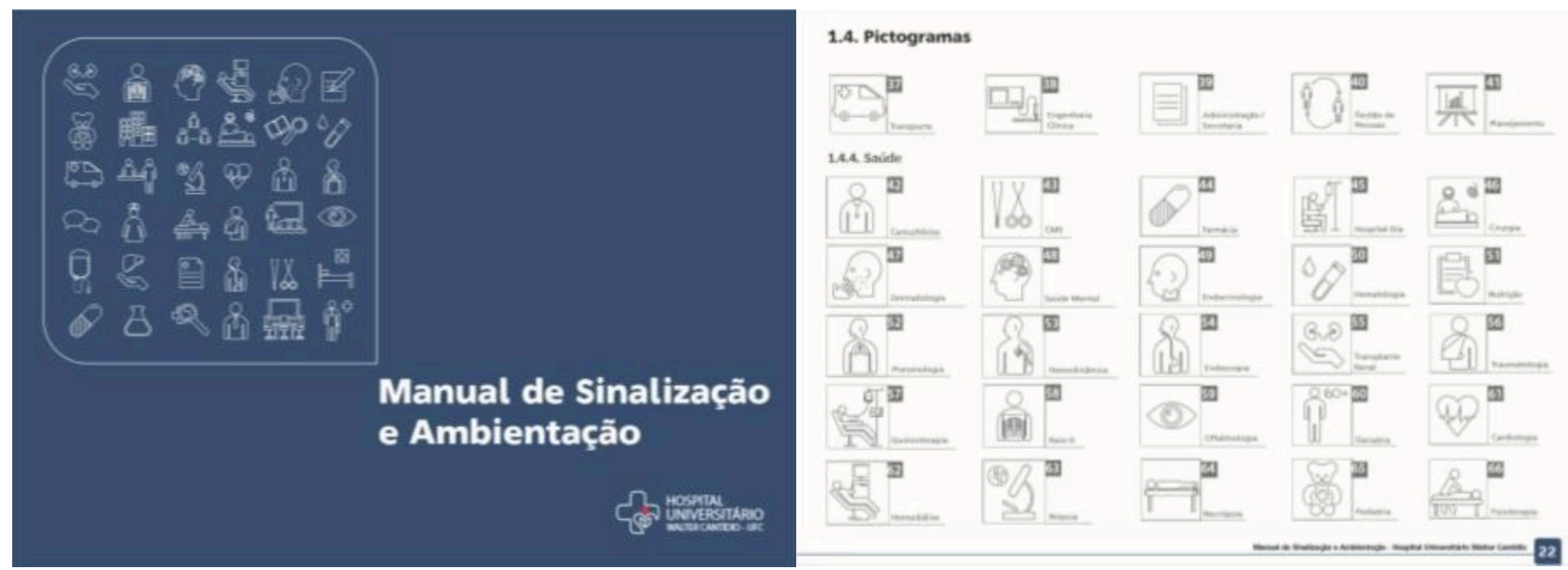

Figura 14 - Páginas iniciais do manual de sinalização e ambientação do Hospital Universitário Walter Cantídio Fonte: Unidade de Comunicação Social do HUWC.

Assim, a pesquisa resultou na construção de uma proposta metodológica de projeto de sinalização aplicável ao Hospital Universitário Walter Cantídio, às demais unidades da Rede Ebserh e a qualquer outra organização de complexidade similar. Ao ser aplicada, essa metodologia gerou o projeto de sinalização do HUWC e o seu manual de sinalização e ambientação, para padronizar a aplicação do projeto no hospital como um todo, além de servir de importante documento consultivo e executivo a outras instituições, hospitalares ou não. A proposta metodológica também permitiu realizar um diagnóstico situacional da sinalização existente no HUWC - sem padronização, desorganizada e descentralizada - e identificar todas as suas oportunidades de melhoria a fim de propor soluções.

O estudo também apontou que, para desenvolver projetos de sinalização como o do HUWC, são necessários: envolvimento e apoio da gestão, equipe multidisciplinar e equipamentos e softwares específicos. Uma estrutura, a princípio, complexa demais para ser viabilizada em menos de um ano na esfera pública (como foi o caso deste trabalho), mas possível quando se identificam oportunidades e se estabelecem parcerias. A construção da rede de apoio, inclusive, foi a contribuição mais inovadora à proposta metodológica.

Outro diferencial inovador deste trabaIho foi a solução financeira encontrada em alternativa à ausência de recursos próprios da instituição, com vista a executar o projeto de sinalização do HUWC. A liberação de R\$ 250 mil via emenda parlamentar individual mostrou, mais uma vez que, na iniciativa pública, as parcerias podem ser a solução de muitos problemas. 


\section{CONSIDERAÇÕES FINAIS}

A experiência vivida na construção do projeto de sinalização do Hospital Universitário Walter Cantídio mostrou que é possível fazer a diferença na gestão pública com inovação, parcerias, criatividade e senso de oportunidade. Esta pesquisa poderia ter se limitado à proposta metodológica do projeto de sinalização do HUWC, mas ela foi muito além.

A condução do processo licitatório, por exemplo, foi um grande aprendizado, como tudo nesse projeto, que foi absolutamente desafiador. O mais adequado seria a conclusão do projeto de sinalização para só então dar início ao processo licitatório, para evitar inconsistências entre o planejado e o executado. Entretanto, como o orçamento é de emenda parlamentar, com prazo de execução até 31 de dezembro de 2018, foi preciso preparar a documentação em paralelo ao projeto de sinalização, tendo em vista que o processo licitatório leva em torno de seis a oito meses para ser concluído no Complexo Hospitalar da UFC, segundo informações da própria Gerência Administrativa. Apesar de ainda não ter sido concluído, avançou bastante, estando já na sua fase final.

Foi preciso aprender, testar, perguntar, pedir apoio, tentar. Crescimento este que fica para outros processos. Inclusive, tudo foi feito sem que a Unidade de Comunicação Social tivesse $\mathrm{O}$ seu funcionamento prejudicado, sendo esta uma experiência desafiadora do ponto de vista de gestão e de organização operacional da unidade.

Outro aprendizado foi a definição de uma proposta metodológica adequada à realidade do Hospital Universitário, com ajustes ao longo do processo. Isso ocorreu sempre com a participação da comunidade hospitalar, para o projeto acontecer, ser aceito, praticado e respeitado. Lembrando que, mesmo democrático, o projeto sofreu e ainda sofrerá, quando executado, com a desconfiança e outros obstáculos impostos pela comunidade hospitalar. No entanto, isso não fez e não pode fazer nenhum projeto fraquejar.

Uma consideração extremamente relevante: a Comunicação ou qualquer outra área que aceite o desafio da sinalização não pode fazê-lo sozinha. Se setores como arquitetura, assistência e orçamento não se envolverem do começo ao fim, é impossível seguir em frente com o projeto. Por fim, fica aqui o compromisso de acompanhar o processo licitatório do HUWC até a sua conclusão, para que se possa executar o projeto e estudar o impacto dele para a comunidade hospitalar, além de estabelecer de maneira mais sistemática as formas de manutenção e controle dessa sinalização. Esse é um compromisso de quem acredita num serviço público de qualidade e que melhore a vida das pessoas. 


\section{REFERÊNCIAS}

ADAMS, A. Decoding modern hospitals: an architectural history.

Architectural Design, v. 87, p. 16-23, 2017.

ALVAREZ, J. Visual design: a step towards multicultural health care.

Archivos Argentinos de Pediatría, v. 112, n. 1, p. 33 - 40, 2014.

AMORA, A. A. The modern architecture focused on health and the city. Magazine IPH, v. 11, p. $98-110,2014$.

ANNEMANS, M. et al. How can research on patient experience inform hospital design? A case study on improving wayfinding. In:

INTERNATIONAL CONFERENCE ON ARCHITECTURE, RESEARCH, CARE, HEALTH, 3., 2017, Copenhagen. Proceedings [...]

Copenhagen: Danish Building Research Institute, 2017. p. 345 - 357.

ASSOCIAÇÃO BRASILEIRA DE NORMAS TÉCNICAS - ABNT. NBR

13.434: sinalização de segurança contra incêndio e pânico. Rio de Janeiro, 2004.

BONFANTI, A. et al. Servicescape navigation: a customer typology based on the wayfinding ability of Italian hospital visitors. The TOM Journal, v. 29, n. 4, p. 546- 563, 2017.

BORGES, M. A.; SILVA, F. M. User-sensing as part of a wayfinding design process. Procedia Manufacturing, v. 3, p. 5912 - 5919, 2015.

CALORI, C. Signage and wayfinding design: a complete guide to creating environmental graphic design systems. Hoboken: Wiley, 2007.

CHAMMA, N.; PASTORELO, P. Marcas e sinalização: práticas em design corporativo. São Paulo: Senac, 2007.

COSTA, J. Señalética corporativa. Barcelona: Costa Punto Com, 2007.

D’AGOSTINI, D. Design de sinalização. São Paulo: Blucher, 2017.

FELLNER, I.; HUANG, H.; GARTNER, G. "Turn left after the WC, and use the

lift to go to the 2nd floor": generation of landmark-based route instructions for indoor navigation. International Journal of GeoInformation, v. 6, p. 183 - 205, 2017. 
FEWINGS, R. Wayfinding and airport terminal design. The Journal of Navigation, v. 54, n. 2, p. 177 -184, 2001.

FOLLIS, J.; HAMMER, D. Architectural signing and graphics. New York: Whitney Library of Design, 1979.

GIBSON, D. The wayfinding handbook: Information design for public places. New York: Princeton Architectural Press, 2009.

GUERRA NETO, C. L. B. (org.). Gestão e inovação em saúde: o que estamos fazendo na Ebserh. Natal: SEDIS-UFRN, 2018.

GWYNNE, S.; GALEA, E. The collection and analysis of premovement times derived from evacuation trials involving university and hospital premises and their application to evacuation modelling. London: CSM Press, 2001.

IMRIE, R.; HALL, P. Inclusive design: designing and developing accessible environments. London: Taylor \& Francis, 2004.

JOY LO, C.; YIEN, H.; CHEN, I. How universal are universal symbols? An estimation of cross-cultural adoption of universal healthcare symbols. Health Environments Research \& Design Journal, v. 9, n. 3, p. $116-134,2016$.

LEONARD, A. L.; VERSTER, A.; COETZEE, M. Developing familyfriendly signage in a South African pediatric healthcare setting. Curationis, v. 37, n. 2, p. $1-7,2014$.

MARKUN, P. Planta baixa. 2014. Disponível em:

http://arquiteturaurbanismotodos.org.br/planta-baixa/. Acesso em: 21 jul. 2018.

MARQUEZ, D. X. et al. Older Adult Strategies for Community Wayfinding. Journal of Applied Gerontology, v. 36, n. 2, p. $213-$ 233, 2017.

MINISTÉRIO DO PLANEJAMENTO, DESENVOLVIMENTO E GESTÃO - MPOG. Instrução Normativa $\mathbf{N}^{\circ} \mathbf{5}$, de 25 de maio de 2017. Dispõe sobre as regras e diretrizes do procedimento de contratação de serviços sob o regime de execução indireta no âmbito da Administração Pública federal direta, autárquica e fundacional. Brasília, 2017.

MINISTÉRIO DO TRABALHO E EMPREGO - MTE. NR 10: segurança em instalações e serviços em eletricidade. Brasília, 2016. 
MOLLERUP, P. Wayshowing: a guide to environmental signage principles and practices. Baden: Lars Müller, 2005.

MORA, R.; OATS, A.; MARZIANO, P. Percepción de la señalización y orientación espacial de los usuarios de tres complejos hospitalarios de Santiago, Chile. Revista Medica de Chile, v. 142, p. 1291 - 1296, 2014.

NEVES, J. et al. Ergonomics and Information Design: design, standardization and uniformization of graphical symbols for public information. In: REBELO, F.; SOARES, M. Advances in Ergonomics in Design. Florida: Springer, 2016. p. 615 - 623.

PROULX, G. Movement of people: the evacuation timing. In: DINENNO, P. J. et al. SFPE handbook of fire protection engineering. Quincy, MA: National Fire Protection Association, p. $342-366,2002$.

PROULX, G.; SIME, J. To prevent 'panic' in an underground emergency: why not tell people the truth?. Fire Safety Science, v. 3, p. $843-852,1991$.

REAY, S. et al. Designing the future of healthcare together: prototyping a hospital co-design space. CoDesign - International Journal of CoCreation in Design and the Arts, v. 13, n. 4, p. 1 - 18, 2017.

SCHERER, F. V.; CATTANI, A.; SILVA, T. L. K. O papel do usuário em metodologias de projeto de sinalização. Brazilian Journal of Information Design, v. 17, n. 2, p. $173-186,2017$.

SCHUSTER, M.; ELROY, I.; ELMAKAIS, I. We are lost: measuring the accessibility of signage in public general hospitals. Lang Policy, v. 16, p. $23-38,2017$.

SHORT, E. J.; REAY, S.; GILDERDALE, P. Wayfinding for health seeking: exploring how hospital wayfinding can employ communication design to improve the outpatient experience. The Design Journal, Roma, v. 20, p. 2.551 - 2.568, 2017.

SMITSHUIJZEN, Edo. Signage Design Manual. Baden: Lars Müller, 2007.

UEBELE, A. Signage system \& information graphics. London: Thames \& Hudson, 2007.

ULRICH, R. et al. The role of the physical environment in the hospital of the 21st century: a once-in a-lifetime opportunity. Atlanta: Georgia Institute of Technology, 2004. 
YANYU, W.; KETAI, H.; AILAN, F. Integrated solution of digital signage application in hospitals. Advanced Materials Research, v. 816/817, p. $588-593,2013$. 